Article

\title{
Nickel Extraction from Olivine: Effect of Carbonation Pre-Treatment ${ }^{\dagger}$
}

\author{
Rafael M. Santos ${ }^{1,2, *}$, Aldo Van Audenaerde ${ }^{2}$, Yi Wai Chiang ${ }^{3}$, Remus I. Iacobescu ${ }^{4}$, \\ Pol Knops ${ }^{5}$ and Tom Van Gerven ${ }^{2}$
}

1 School of Applied Chemical and Environmental Sciences, Sheridan Institute of Technology, Brampton, ON L6Y 5H9, Canada

2 Department of Chemical Engineering, KU Leuven, Leuven 3001, Belgium;

E-Mails: aldovanaudenaerde@gmail.com (A.V.A.); tom.vangerven@cit.kuleuven.be (T.V.G.)

3 School of Engineering, University of Guelph, Guelph, ON N1G 2W1, Canada;

E-Mail: chiange@uoguelph.ca

4 Department of Materials Engineering, KU Leuven, Leuven 3001, Belgium;

E-Mail: remusion.iacobescu@mtm.kuleuven.be

5 Innovation Concepts B.V., Twello 7391MG, The Netherlands;

E-Mail: knops@innovationconcepts.eu

$\dagger$ Contents of this paper also appear in the MetSoc of CIM Proceedings of the 7th International Symposium-Hydrometallurgy 2014, Volume II, pp. 755-767.

* Author to whom correspondence should be addressed; E-Mail: rafael.santos@alumni.utoronto.ca; Tel.: +1-905-459-7533 (ext. 5723); Fax: +1-905-874-4321.

Academic Editors: Suresh Bhargava and Rahul Ram

Received: 19 August 2015 / Accepted: 6 September 2015 / Published: 11 September 2015

\begin{abstract}
In this work, we explore a novel mineral processing approach using carbon dioxide to promote mineral alterations that lead to improved extractability of nickel from olivine $\left((\mathrm{Mg}, \mathrm{Fe})_{2} \mathrm{SiO}_{4}\right)$. The precept is that by altering the morphology and the mineralogy of the ore via mineral carbonation, the comminution requirements and the acid consumption during hydrometallurgical processing can be reduced. Furthermore, carbonation pre-treatment can lead to mineral liberation and concentration of metals in physically separable phases. In a first processing step, olivine is fully carbonated at high $\mathrm{CO}_{2}$ partial pressures (35 bar) and optimal temperature $\left(200{ }^{\circ} \mathrm{C}\right)$ with the addition of $\mathrm{pH}$ buffering agents. This leads to a powdery product containing high carbonate content. The main products of the carbonation
\end{abstract}


reaction include quasi-amorphous colloidal silica, chromium-rich metallic particles, and ferro-magnesite $\left(\left(\mathrm{Mg}_{1-x}, \mathrm{Fe}_{x}\right) \mathrm{CO}_{3}\right)$. Carbonated olivine was subsequently leached using an array of inorganic and organic acids to test their leaching efficiency. Compared to leaching from untreated olivine, the percentage of nickel extracted from carbonated olivine by acid leaching was significantly increased. It is anticipated that the mineral carbonation pre-treatment approach may also be applicable to other ultrabasic and lateritic ores.

Keywords: nickel; olivine; mineral carbonation; leaching; ferro-magnesite; colloidal silica

\section{Introduction}

In the last few decades, traditional nickel resources have become scarcer because of ramping global production and growing demand [1]. Nickel is more abundantly present in the Earth's crust than copper and lead, but the availability of high-grade ores is rather limited [2]. The current strong demand for nickel is expected to carry into the future, and the scarcity of high-grade recoverable ores will inevitably call for the exploitation of low-grade ores as a source for nickel. Therefore, increasingly more research is underway investigating the feasibility of recovering nickel from low-grade ores [3-5]. Magnesium-iron silicates, minerals that are widely distributed on the Earth's crust and that contain relatively dilute, yet considerable amounts, of nickel arise as one possible, yet challenging, opportunity.

The main objective of this study was to investigate the possibility of processing olivine $\left((\mathrm{Mg}, \mathrm{Fe})_{2} \mathrm{SiO}_{4}\right)$ for the production of nickel. Olivine is solid-solution of iron- and magnesium-silicates containing relatively small amounts of nickel and chromium, and is the precursor of weathered lateritic ores. Olivine (also known as dunite, an ore containing at least $90 \%$ olivine [6]) is abundantly present in the Earth's upper mantle [7], and intrudes in some locations into the Earth's crust, most notably in the Fjordane Complex of Norway, which contains the largest ore body (approx. two billion metric tons) under commercial exploitation [6]. The use of olivine as a nickel source could, thus, possibly solve the scarcity problem of high-grade ores. Due to its small nickel content, conventional extraction and recovery methods (e.g., high pressure acid leaching, agitation leaching or heap leaching [3]) are not viable, as reagent and processing costs become too high [8]. In this work a novel approach was investigated, whereby the mineral is first carbonated in a pre-treatment step before the nickel is extracted by leaching. Carbonation may allow for an easier recovery due to a better accessibility of the nickel during leaching as a result of morphological and mineralogical changes. Recently, considerable research has focused on the carbonation of olivine and other alkaline silicates as an option for sustainable carbon dioxide sequestration $[9,10]$. In the present work, however, $\mathrm{CO}_{2}$ is utilized primarily as a processing agent; such an approach can be termed "carbon utilization" (more specifically turning $\mathrm{CO}_{2}$ from a waste into an acid).

Nickel is able to replace magnesium in olivine's magnesium silicate matrix forming a magnesium-nickel silicate $(\mathrm{Mg}, \mathrm{Ni})_{2} \mathrm{SiO}_{4}$ called liebenbergite or nickel-olivine. This replacement is possible due to certain similarities of nickel and magnesium in the silicate structure. Their ionic radii are similar $(\mathrm{Mg}=0.66 \AA ; \mathrm{Ni}=0.69 \AA)$, their valences are the same $\left(\mathrm{Mg}^{2+}, \mathrm{Ni}^{2+}\right)$, and they both belong to the same orthorhombic system [11]. The amount of nickel in olivine is variable and depends on the ore's 
origin, varying between $<0.1$ and $0.5 \mathrm{wt}$. $\% \mathrm{Ni}$ [12]. These concentrations are rather low compared to the grade of nickel deposits presently used in industrial processes, which ranges from 0.7 to 2.7 wt. $\% \mathrm{Ni}[11]$.

Olivine is highly susceptible to weathering processes and alterations by hydrothermal fluids. These alteration reactions involve hydration, silicification, oxidation, and carbonation; common alteration products are serpentine, chlorite, amphibole, carbonates, iron oxides, and talc [11]. The fact that olivine is highly susceptible to weathering also makes it suitable for intensified carbonation. Due to this suitability and its high abundance, olivine has been the subject of intensive research for carbon dioxide sequestration using mineral carbonation, whereby the formation of stable magnesium carbonates act as carbon sinks [13-17].

Carbonating olivine converts the silicates (mainly forsterite $\left(\mathrm{Mg}_{2} \mathrm{SiO}_{4}\right)$ and fayalite $\left(\mathrm{Fe}_{2} \mathrm{SiO}_{4}\right)$ [6]) into carbonates and silica. This reaction is exothermic and is, thus, thermodynamically favored. The reaction mechanism contains three main steps: the dissolution of $\mathrm{CO}_{2}$ in the aqueous solution to form carbonic acid; the dissolution of magnesium in the aqueous solution, and the precipitation of magnesium carbonate. The overall reaction schemes for carbonation of forsterite and fayalite are given in Equations (1) and (2):

$$
\begin{gathered}
\mathrm{Mg}_{2} \mathrm{SiO}_{4}+2 \mathrm{CO}_{2} \rightleftharpoons 2 \mathrm{MgCO}_{3}+\mathrm{SiO}_{2}+89 \mathrm{~kJ} / \mathrm{mol} \mathrm{CO}_{2} \\
\mathrm{Fe}_{2} \mathrm{SiO}_{4}+2 \mathrm{CO}_{2} \rightleftharpoons 2 \mathrm{FeCO}_{3}+\mathrm{SiO}_{2}+79 \mathrm{~kJ} / \mathrm{mol} \mathrm{CO}_{2}
\end{gathered}
$$

The formed magnesite $\left(\mathrm{MgCO}_{3}\right)$ and siderite $\left(\mathrm{FeCO}_{3}\right)$, as well as the residual silica $\left(\mathrm{SiO}_{2}\right)$, are thermodynamically stable products that are environmentally friendly. These reaction products can, thus, be readily disposed of in the environment or reutilized as commercial products.

The focus of this work was to investigate the leaching behavior of carbonated olivine. When carbonated olivine is leached, the acid will have to dissolve a carbonate structure instead of a silicate structure. These reactions can be seen in Equations (3) and (4):

$$
\begin{aligned}
& \mathrm{MgCO}_{3}+2 \mathrm{H}^{+} \rightleftharpoons \mathrm{Mg}^{2+}+\mathrm{CO}_{2}(\mathrm{~g})+\mathrm{H}_{2} \mathrm{O} \\
& \mathrm{MgCO}_{3}+2 \mathrm{H}^{+} \rightleftharpoons \mathrm{Mg}^{2+}+\mathrm{CO}_{2}(\mathrm{~g})+\mathrm{H}_{2} \mathrm{O}
\end{aligned}
$$

Through these alterations of the olivine mineral, which may increase specific surface area, nickel might become more accessible to leaching. Secondly, the $\mathrm{C}-\mathrm{O}(360 \mathrm{~kJ} / \mathrm{mol})$ bonds are weaker than their $\mathrm{Si}-\mathrm{O}(466 \mathrm{~kJ} / \mathrm{mol})$ counterparts [18], which can lead to an easier leaching of the carbonated olivine compared to natural olivine.

This paper reports the results of a series of tests that aimed to: (i) find the optimal carbonation conditions that maximize the desired mineral and morphological alterations; (ii) characterize the carbonated products with a focus on the fate of nickel; (iii) compare the leaching performance of an array of organic and inorganic acids, and assess the efficiency and extent of nickel extraction from carbonated olivine compared to natural olivine; and (iv) provide the proof-of-concept of using carbonation as a pre-treatment step for nickel recovery from low-grade silicate ores and elucidate directions for future research. 


\section{Experimental Section}

\subsection{Olivine Characterization}

Olivine was supplied by Eurogrit B.V. (a subsidiary of Sibelco, Antwerp, Belgium) and originated from Åheim, Norway. The material obtained, classified as GL30, had the following properties described by the supplier: sub-angular to angular shape, pale green color, hardness of 6.5 to 7 Mohs, specific density of $3.25 \mathrm{~kg} / \mathrm{dm}^{3}$, and a grain size between 0.063 and $0.125 \mathrm{~mm}$. The olivine was milled before any further use to increase the reactivity of the material to carbonation and leaching by increasing the specific surface area. The milling was performed using a centrifugal mill (Retsch ZM100, Haan, Germany) operated at $1400 \mathrm{rpm}$ with an $80 \mu \mathrm{m}$ sieve mesh. After milling, a total of $86 \mathrm{vol}$. \% of the material had a particle size below $80 \mu \mathrm{m}$, and the average mean diameter $\mathrm{D}\{4,3\}$, determined by Laser Diffraction Analysis (LDA, Malvern Mastersizer 3000, Worcestershire, UK), was equal to $34.8 \mu \mathrm{m}$. The particle size distribution is shown in Figure S1. The morphology of the particles was imaged by Scanning Electron Microscopy (SEM, Philips XL30 FEG, Eindhoven, The Netherlands), and is shown in Figure S2. For SEM analysis, particles were gold-coated and mounted on conductive carbon tape.

The material was extensively analyzed to obtain the chemical and mineralogical composition. Table 1 presents the elemental composition results obtained by digestion followed by Inductively-Coupled Plasma Mass Spectrometry (ICP-MS, Thermo Electron X Series, Waltham, MA, USA) analysis; $\mathrm{Co}, \mathrm{Mg}, \mathrm{Mn}$, and $\mathrm{Si}$ content were determined by Wavelength Dispersive X-ray Fluorescence (XRF, Panalytical PW2400, Almelo, The Netherlands).

Table 1. Elemental composition of fresh olivine, in decreasing order, determined by ICP-MS (Al, Ca, Cr, Fe, Ni) and XRF * (Co, Mg, Mn, Si).

\begin{tabular}{cc}
\hline Element & Mass \% \\
\hline $\mathrm{Mg}$ & 27.2 \\
$\mathrm{Si}$ & 20.7 \\
$\mathrm{Fe}$ & 3.7 \\
$\mathrm{Ni}$ & 0.27 \\
$\mathrm{Cr}$ & 0.24 \\
$\mathrm{Al}$ & 0.17 \\
$\mathrm{Ca}$ & 0.17 \\
$\mathrm{Mn}$ & 0.09 \\
$\mathrm{Co}$ & 0.02 \\
\hline
\end{tabular}

* XRF was used for $\mathrm{Si}$ and Mg analysis as it is a more accurate method for determination of these elements. Data for Co and Mn is not available by ICP-MS, so XRF data is presented; it should be noted that due to their low concentration, these data are to be considered semi-quantitative.

The mineralogy of the fresh olivine was analyzed by powder X-ray Diffraction (XRD, Philips PW1830, Almelo, The Netherlands) with quantification by Rietveld refinement; the diffractogram is shown in Figure 1. As can be expected, the material contains mostly forsterite $(84.5 \mathrm{wt}$ \% ; in fact ferroan-forsterite, which is forsterite with iron substitution) as well as a smaller amount of fayalite (2.5 wt. \%). Other minor components present include some hydrated silicates (clinochlore $\left(\left(\mathrm{Mg}, \mathrm{Fe}^{2+}\right)_{5} \mathrm{Al}\left(\mathrm{Si}_{3} \mathrm{Al}\right) \mathrm{O}_{10}(\mathrm{OH})_{8}, 2.1\right.$ wt. \%), lizardite $\left(\mathrm{Mg}_{3} \mathrm{Si}_{2} \mathrm{O}_{5}(\mathrm{OH})_{4}, 2.7\right.$ wt. \%), talc $\left(\mathrm{Mg}_{3} \mathrm{Si}_{4} \mathrm{O}_{10}(\mathrm{OH})_{2}\right.$, 
0.5 wt. \%), and tirodite $\left(\mathrm{Na}\left(\mathrm{Na}, \mathrm{Mn}^{2+}\right)\left(\mathrm{Mg}_{4}, \mathrm{Fe}^{2+}\right) \mathrm{Si}_{8} \mathrm{O}_{22}(\mathrm{OH})_{2}\right.$, 3.1 wt. \%)), carbonates (magnesian calcite $\left(\mathrm{Ca} 0.85 \mathrm{Mg}_{0.15} \mathrm{CO}_{3}, 1.0\right.$ wt. \%), and magnesite $\left(\mathrm{MgCO}_{3}, 0.2\right.$ wt. \%)), magnesium (hydr)oxides (periclase ( $\mathrm{MgO}, 0.1$ wt. \%), and brucite $\left(\mathrm{Mg}(\mathrm{OH})_{2}, 0.7\right.$ wt. \%)), chromite $\left(\mathrm{FeCr}_{2} \mathrm{O}_{4}, 1.1\right.$ wt. \%) and quartz $\left(\mathrm{SiO}_{2}, 0.2\right.$ wt. \%).

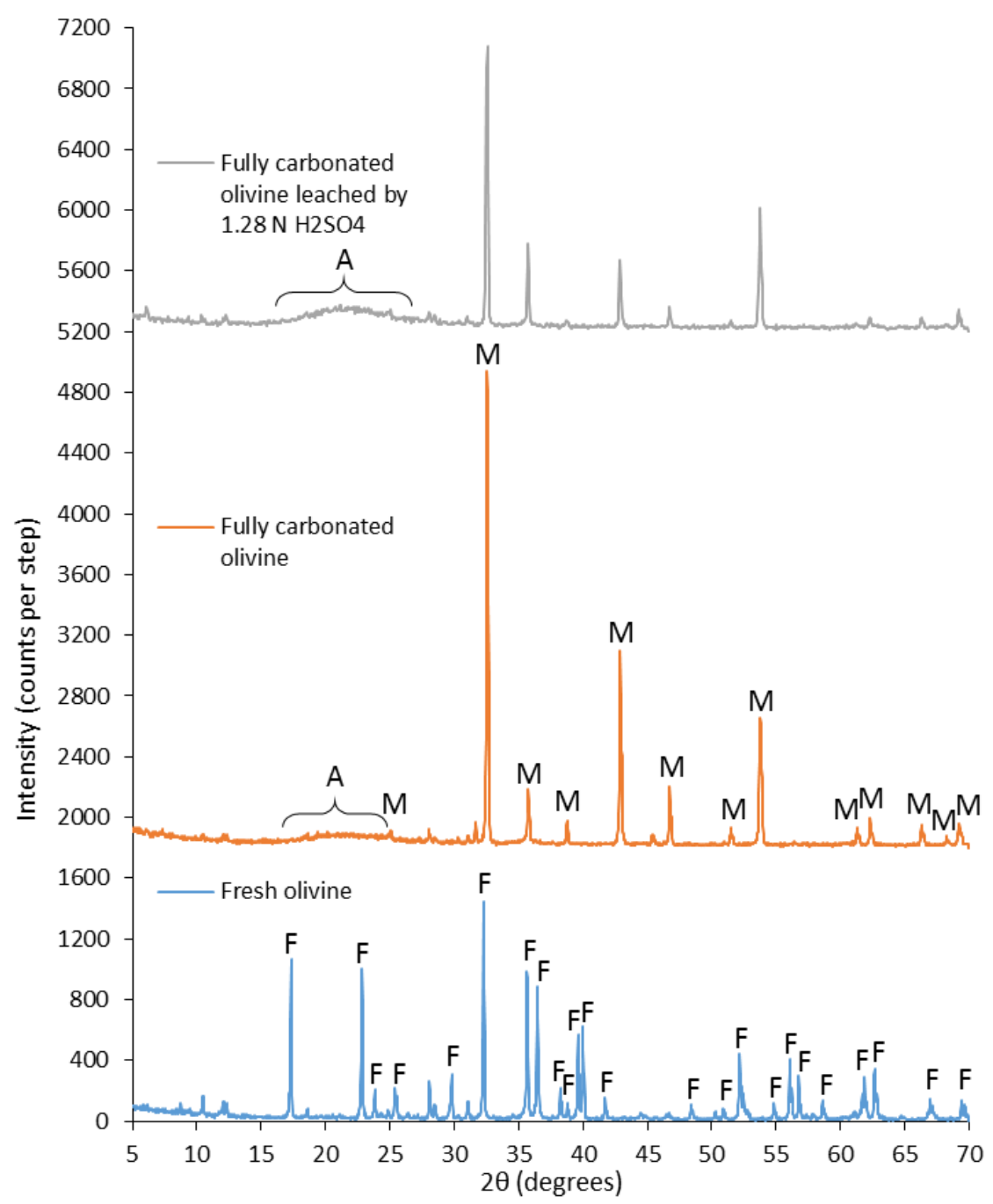

Figure 1. XRD diffractograms of fresh olivine, fully carbonated olivine and fully carbonated olivine after leaching in $1.28 \mathrm{~N} \mathrm{H}_{2} \mathrm{SO}_{4}$ for $24 \mathrm{~h}$; major mineral peaks are indicated: $\mathrm{F}=$ ferroan-forsterite $\left((\mathrm{Mg}, \mathrm{Fe})_{2} \mathrm{SiO}_{4}\right) ; \mathrm{M}=$ magnesite/ferro-magnesite $\left(\left(\mathrm{Mg}_{1-x}, \mathrm{Fe}_{x}\right) \mathrm{CO}_{3}\right) ; \mathrm{A}=$ quasi-amorphous phase.

The olivine was also analyzed with a Jeol Hyperprobe JXA-8530F Field Emission Gun Electron Probe Micro-Analyzer (FEG EPMA, Akishima, Japan), equipped with five wavelength dispersive spectrometers, to map the concentration of each element within the particles. The EPMA was capable of detecting elements down to a concentration of $100 \mathrm{ppm}$ and map them down to a spatial resolution of $0.1 \mu \mathrm{m}$. A small representative surface area $(80 \times 100 \mu \mathrm{m})$ of a polished sample (pelletized and embedded in resin) was fully mapped to give the distribution of elements in the material. The EPMA was operated at $15 \mathrm{kV}$, a probe current of $100 \mathrm{nA}$, and dwell time of $30 \mathrm{~ms}$ per $0.3 \times 0.3 \mu \mathrm{m}$ pixel. Both peak and background were measured under these conditions. Nickel was found to be dispersed in the material, as can be seen in Figure 2. This would indicate that it replaces magnesium in the magnesium silicate 
structure to form a magnesium-nickel silicate $\left((\mathrm{Mg}, \mathrm{Ni})_{2} \mathrm{SiO}_{4}\right)$. There are also small particles that are highly concentrated (shown as white) in nickel, chromium and iron. Figure S3 shows the elemental distribution of other elements ( $\mathrm{Al}, \mathrm{C}, \mathrm{Ca}, \mathrm{Co}, \mathrm{Cr}, \mathrm{Fe}, \mathrm{Mg}, \mathrm{Mn}, \mathrm{Si}$ ). Figure S4 helps to visualize that nickel-rich regions exist; in some, nickel is associated with iron (cyan color in composite map), and in some nickel is not associated with iron nor chromium (green color in composite map). In the case of chromium, it is present mainly in select regions, and those regions are highly concentrated in iron as well (suggestive of chromite), but not in nickel.

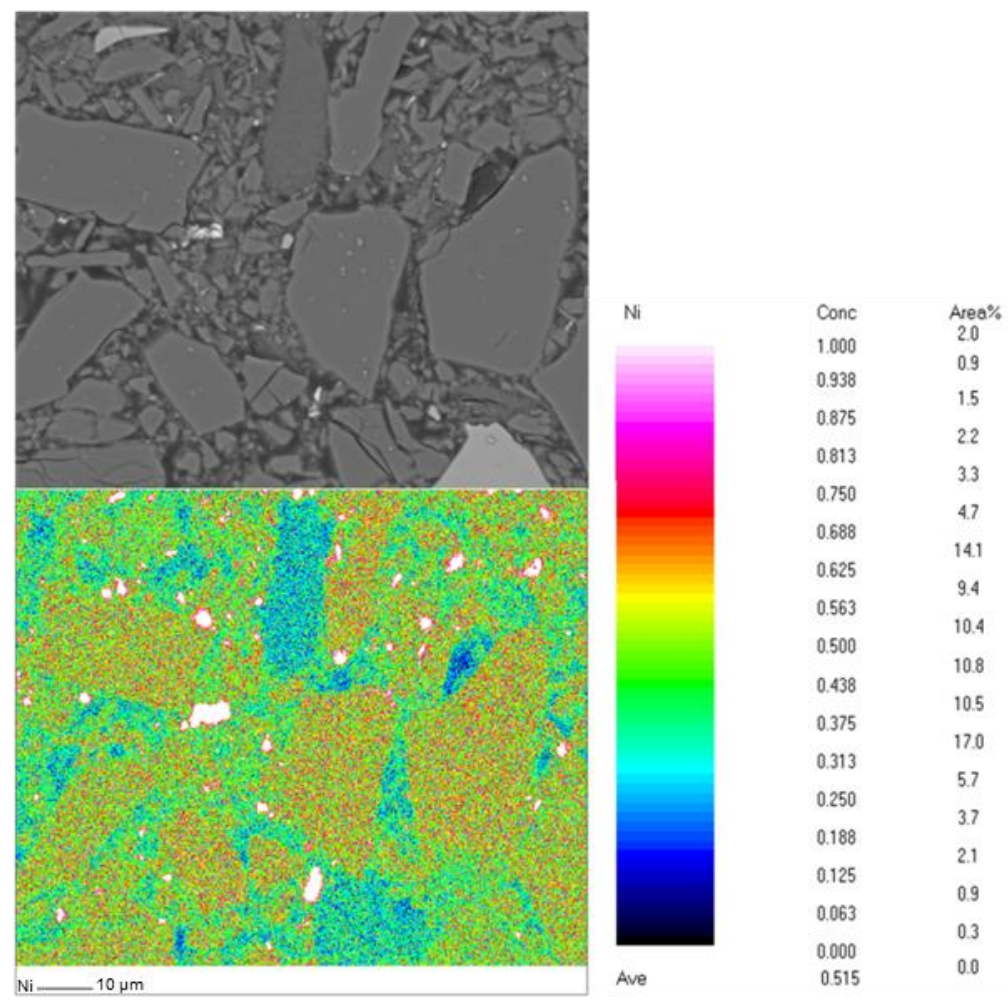

Figure 2. Fresh olivine backscattered scanning electron image (top) and EPMA mapping of nickel concentrations (bottom); concentration scale is relative to max/min levels.

\subsection{Carbonation}

Carbonation experiments were conducted in a Büchi Ecoclave continuously-stirred tank reactor (CSTR, Uster, Switzerland). The reactor has a volume of 1.1 liters and is capable of withstanding pressures up to 60 bar and temperatures up to $250{ }^{\circ} \mathrm{C}$. Carbon dioxide gas $(99.5 \%$ purity) was continuously injected from a compressed cylinder. It should be noted that for industrial implementation, gases with lower $\mathrm{CO}_{2}$ purity (e.g., combustion flue gases) may be used for mineral carbonation so long as the desired $\mathrm{CO}_{2}$ partial pressure is met by gas compression. All experiments in this study were conducted with 35 bar $\mathrm{CO}_{2}$ partial pressure; steam made up the balance pressure up to 55 bar total, depending on the temperature. The reactor was equipped with a Rushton turbine stirrer and a baffle to ensure adequate mixing of the reactor contents; $1000 \mathrm{rpm}$ stirring rate was used. The liquid volume in the reactor was kept constant at $800 \mathrm{~mL}$.

The experimental parameters varied are detailed in Table 2; these were temperature, solids loading, residence time, and additive concentrations. Increasing the temperature influences the equilibrium 
constants. An increase in the dissociation constants of carbonic acid leads to a decrease in $\mathrm{pH}$ (higher acidity) and an increase in both bicarbonate and carbonate ion concentrations; this enhances the dissolution of magnesium as well as the precipitation of magnesium carbonate (under suitable $\mathrm{pH}$, i.e., not excessively acidic). These effects are counteracted by an increase of Henry's constant, which leads to a lower solubility of $\mathrm{CO}_{2}$ in the solution. Lastly, a decrease of the solubility product of magnesium carbonate stimulates its precipitation. These opposing effects indicate that an optimal temperature exists. Increasing the solids loading in the reaction process has been reported to increase the extent of carbonation due to an increase in particle-particle collisions that remove passivating layers and increase the surface area available for carbonation [19]. The use of additives aims at enhancing the dissolution of magnesium, the dissociation of carbonic acid, and/or the precipitation of magnesium carbonate. Sodium chloride $(\mathrm{NaCl})$ and sodium bicarbonate $\left(\mathrm{NaHCO}_{3}\right)$ were tested as carbonation enhancing additives as suggested by Chen et al. [20].

After completion, the reacted slurry content was filtered to recover the liquid and solid portions; solids were dried at $105{ }^{\circ} \mathrm{C}$ for $24 \mathrm{~h}$. Most experiments were conducted in duplicate, and data presented are average values.

Table 2. Parameter values used in the carbonation experiments.

\begin{tabular}{cc}
\hline Parameters & Tested Values \\
\hline Temperature & $150-185-200{ }^{\circ} \mathrm{C}$ \\
Solids loading & $50-100-200 \mathrm{~g} / 800 \mathrm{~mL}$ \\
Residence time & $4-24-48-72 \mathrm{~h}$ \\
$\mathrm{NaCl}$ concentration & $0-1-2 \mathrm{M}$ \\
$\mathrm{NaHCO}_{3}$ concentration & $0-0.64-2.5 \mathrm{M}$ \\
\hline
\end{tabular}

\subsection{Leaching}

Leaching experiments were conducted by atmospheric agitation methodology. A certain amount of olivine (typically two grams), either fresh or carbonated, was added to plastic flasks together with $100 \mathrm{~mL}$ of a solution containing various concentrations of a certain acid. The flasks were shaken at $25{ }^{\circ} \mathrm{C}$ for the desired reaction time (typically $24 \mathrm{~h}$ ). When finished, solids and liquids were separated using a centrifuge. The supernatant liquids and the dried solids were further analyzed. Leaching experiments were conducted in duplicate, and data presented are average values. A low leaching temperature was used as this study's main aim was to investigate mineralogical effects on chemical equilibrium rather than leaching kinetics. Low temperature leaching (i.e., ambient) is typical in heap leaching operations [3].

For the leaching with inorganic acids, sulfuric acid $\left(\mathrm{H}_{2} \mathrm{SO}_{4}\right)$, nitric acid $\left(\mathrm{HNO}_{3}\right)$ and hydrochloric acid $(\mathrm{HCl})$ were chosen. A preliminary test was performed using a large variety of organic acids: citric acid $\left(\mathrm{HOC}(\mathrm{COOH})\left(\mathrm{CH}_{2} \mathrm{COOH}\right)_{2}\right)$, oxalic acid $(\mathrm{HOOCCOOH})$, succinic acid $\left(\mathrm{HOOC}\left(\mathrm{CH}_{2}\right)_{2} \mathrm{COOH}\right)$, lactic acid $\left(\mathrm{CH}_{3} \mathrm{CH}(\mathrm{OH}) \mathrm{COOH}\right)$, acetic acid $\left(\mathrm{CH}_{3} \mathrm{COOH}\right)$, formic acid $(\mathrm{HCOOH})$ and butyric acid $\left(\mathrm{C}_{3} \mathrm{H}_{7} \mathrm{COOH}\right)$. These organic acids were chosen as they are reportedly produced by microorganisms utilized in bioleaching of silicate minerals [21,22]. Based on preliminary experimental results (Figure S5) the three most promising organic acids, citric acid, formic acid, and lactic acid were selected for further use in the experiments discussed hereon. 


\subsection{Analytical Methods}

The concentrations of soluble elements in aqueous solutions were determined by ICP-MS. The mineralogical, morphological, and microstructural properties of carbonated solids were characterized by XRD, SEM, nitrogen adsorption (BET, Micromeritics TriStar 3000, Norcross, GA, USA), LDA, and EPMA. The $\mathrm{CO}_{2}$ uptake of the carbonated solids was determined by thermogravimetric analysis (TGA, TA Instruments Q500, New Castle, DE, USA), conducted in duplicate. The weight loss between 250 and $900{ }^{\circ} \mathrm{C}$ was attributed to the decomposition of carbonates (XRD results suggest minimal formation of hydration products that could interfere in this range, and there is good agreement between quantitative XRD and TGA determination of magnesite content (Figure S6)). The maximal theoretical $\mathrm{CO}_{2}$ uptake $\left(M_{\mathrm{CO}_{2} \text {,max }}\right)$ of natural olivine, $0.521 \mathrm{~g}, \mathrm{CO}_{2} / \mathrm{g}$, olivine, was estimated based on its magnesium and iron content. Extent of carbonation $(\xi)$ is expressed as the percentage ratio of actual to maximal uptake values: $\xi=M_{\mathrm{CO}_{2} \text {,actual }} / M_{\mathrm{CO}_{2} \text {, max }}$.

\section{Results and Discussion}

\subsection{Influence of Carbonation Parameters}

The dependencies of the temperature, residence time, solids loading, and $\mathrm{NaCl}$ and $\mathrm{NaHCO}_{3}$ concentrations on the carbonation extent are given in Figure 3.

The influence of the reactor temperature on the carbonation is shown in Figure 3a. The extent of carbonation increases with increasing temperature between $150{ }^{\circ} \mathrm{C}$ and $200{ }^{\circ} \mathrm{C}$, both for $4 \mathrm{~h}$ and $24 \mathrm{~h}$ residence times. This is due to the increase in both acid dissociation constants of carbonic acid, which contributes to magnesium silicate dissolution, as well as the decrease in the solubility product of magnesium carbonate, which promotes magnesium carbonate precipitation. These two effects are mutually beneficial, since as more magnesium precipitates as carbonate, more magnesium can leach from the silicate, propagating the reaction. Increasing the temperature also increases Henry's constant for the dissolution of $\mathrm{CO}_{2}$ in the water, which can have a negative impact on the carbonation [20], but this was not observed here. O'Connor et al. [23] found that these counteracting temperature effects lead to an optimal olivine carbonation temperature of $185{ }^{\circ} \mathrm{C}$. In our experiments, no maximum was reached between $150{ }^{\circ} \mathrm{C}$ and $200{ }^{\circ} \mathrm{C}$. The difference in results can be explained because O'Connor et al. [23] use other parameter values in their experiments; most importantly, they operated at $\mathrm{CO}_{2}$ pressures of 150 bar, whereas our experiments operated at 35 bar. At higher $\mathrm{CO}_{2}$ pressure, the solubility limit of $\mathrm{CO}_{2}$ will be reached at a lower temperature.

The extent of carbonation increases linearly with an increase in residence time, as can be seen in Figure $3 b$. There seems to be an initially fast carbonation rate due to parts of the olivine that are more easily carbonated (fines, particle surfaces, and more reactive minerals (e.g., periclase, brucite)), after which the carbonation continues linearly with time. Due to this linear increase with time, there is either no limitation by the formation of a passivating layer, or the passivating layer is broken down sufficiently by particle collisions. This was confirmed by SEM analysis of partially carbonated olivine. Figure S7 shows that the residual silica and precipitated magnesite form separate particles, rather than forming a passivating layer around unreacted olivine. More discussion on this is presented in the Section 3.2. The residence times used in this study are relatively long, which was necessary because of the relatively low 
$\mathrm{CO}_{2}$ partial pressure utilized ( 35 bar), as restricted by the reactor's pressure rating. Higher $\mathrm{CO}_{2}$ partial pressures should accelerate the processes, from the order of days to the order of hours, as indicated by other studies conducted at higher pressures (e.g., 139 atm [14]) and modeling work [13].

a)

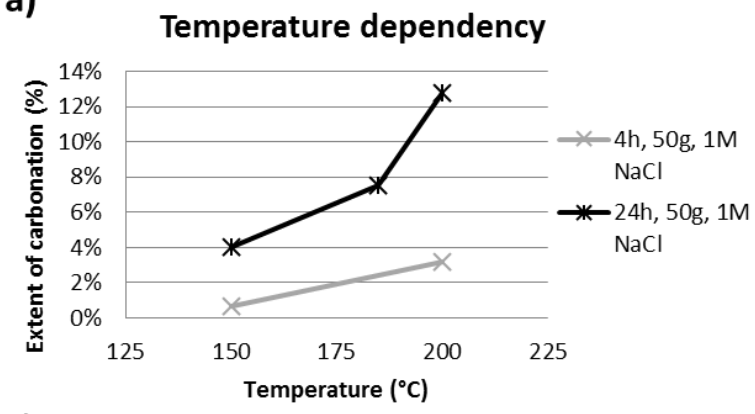

c)

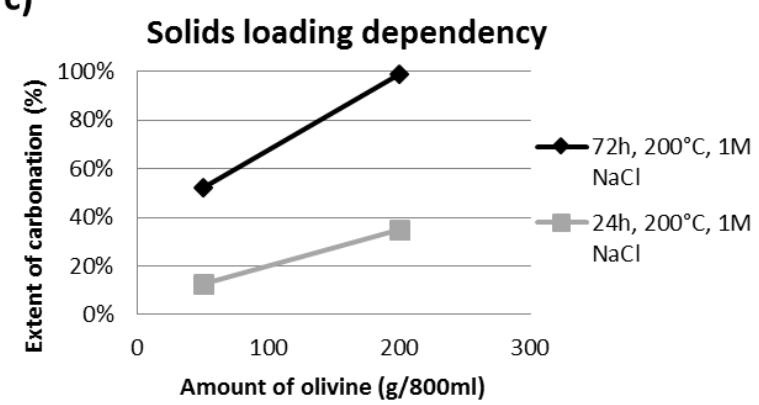

e)

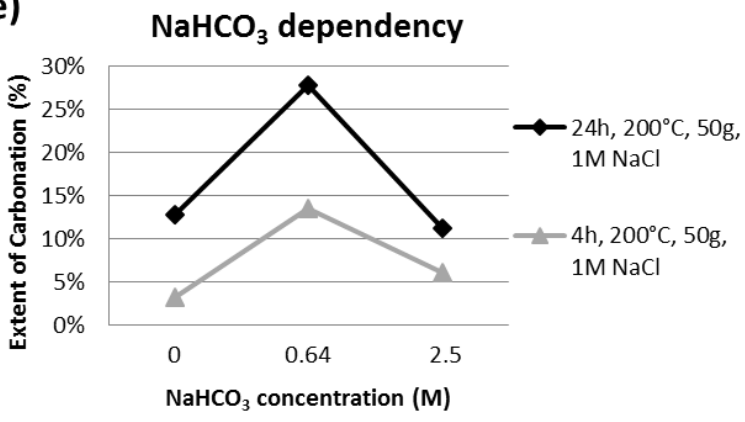

b)

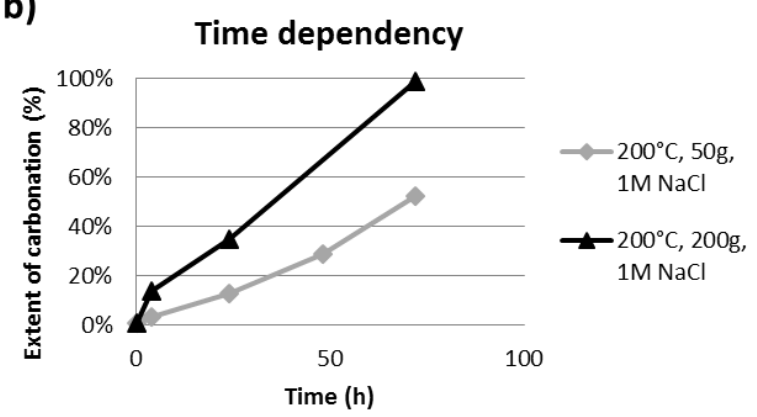

d)

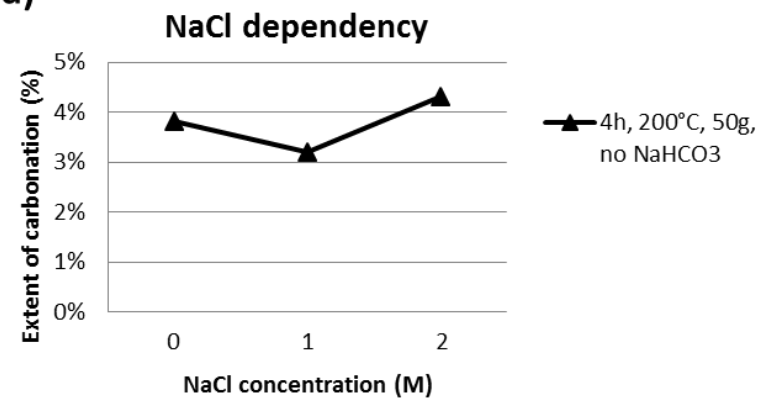

Figure 3. Influence of carbonation process parameters (temperature (a); residence time (b); solids loading (c); $\mathrm{NaCl}$ concentration (d); and $\mathrm{NaHCO}_{3}$ concentration (e)) on extent of olivine carbonation; Table $\mathrm{S} 1$ provides detailed data values and statistics on replicates.

As can be seen from Figure 3c, increasing the solids loading greatly enhances carbonation. A solids loading increase from $50 \mathrm{~g}(5.9 \mathrm{wt}$. \%) to $200 \mathrm{~g}(20 \mathrm{wt}$. \%) almost doubles the carbonation extent for both the $24 \mathrm{~h}$ and $72 \mathrm{~h}$ experiments at $200{ }^{\circ} \mathrm{C}$ with the addition of $1 \mathrm{M} \mathrm{NaCl}$. These results confirm previous results from Béarat et al. [19] who also noticed a substantial increase in carbonation, proportional to (wt. \% $)^{1 / 3}$, when increasing the solids loading from 5 to $20 \mathrm{wt}$. \%. The higher amount of solids in the reactor will lead to more collisions of the olivine particles, promoting the removal of passivating layers and the breakage of unreacted particles. Julcour et al. [16] emphasized the importance of attrition/exfoliation, conducting olivine carbonation reactor in a stirred bead mill and achieving $80 \%$ conversion in $24 \mathrm{~h}$ at $180{ }^{\circ} \mathrm{C}, 800 \mathrm{rpm}$ and $20 \mathrm{bar} \mathrm{CO}_{2}$.

The addition of $\mathrm{NaCl}$ does not seem to enhance the extent of carbonation. As can be seen in Figure 3d, using one or two molar solutions of $\mathrm{NaCl}$ has a very limited impact on the extent of 
carbonation. O'Connor et al. [23] proposed the addition of both $1 \mathrm{M} \mathrm{NaCl}$ and $0.64 \mathrm{M} \mathrm{NaHCO}_{3}$, although they also remarked that the addition of sodium bicarbonate has a much larger impact than sodium chloride on the carbonation extent. It can be concluded that, in view of minimizing processing cost or complexity, $\mathrm{NaCl}$ addition can be omitted. However, ionic strength can play a role in surface charges and particle aggregation, and should, thus, be investigated in view of product properties such as particle size distribution, specific surface area, and mineral separation. An economical source of saline solution, if desired, would be seawater.

The addition of $\mathrm{NaHCO}_{3}$, on the other hand, has a substantial impact on the carbonation reaction. As can be seen from Figure 3e, the extent of carbonation is highest when $0.64 \mathrm{M}$ of $\mathrm{NaHCO}_{3}$ is added. The substantial impact of $\mathrm{NaHCO}_{3}$ on the carbonation is due to its dissolution into $\mathrm{Na}^{+}$and $\mathrm{HCO}_{3}{ }^{-}$ions. Chen et al. [20] state that adding sodium bicarbonate reduces the concentration of magnesium ions required to exceed the solubility product for magnesium carbonate and, thus, promotes the precipitation of magnesite. They explain that this is because in solutions with a large amount of $\mathrm{NaHCO}_{3}$, the concentration of $\mathrm{CO}_{3}{ }^{2-}$ is inversely proportional to $\mathrm{CO}_{2}$ pressure and proportional to the square of the concentration of $\mathrm{NaHCO}_{3}$. A reversal of this effect occurs at higher concentrations of $\mathrm{NaHCO}_{3}$ possibly because the solution $\mathrm{pH}$ increases excessively, slowing the dissolution of the silicate minerals.

\subsection{Characterization of Fully-Carbonated Olivine}

Full conversion $\left(0.515 \mathrm{~g}, \mathrm{CO}_{2} / \mathrm{g}\right.$, olivine $\left.=99.0 \% \pm 3.9 \%\right)$ of olivine was achieved by carbonating it for $72 \mathrm{~h}$ at $200{ }^{\circ} \mathrm{C}$ and 35 bar $\mathrm{CO}_{2}$ partial pressure with the addition of $1 \mathrm{M} \mathrm{NaCl}$ and using a solids loading of $200 \mathrm{~g} / 800 \mathrm{~mL}$. This fully carbonated olivine was the only carbonated material used in the acid leaching experiments presented in Section 3.3. The chemical and mineralogical compositions as well as the microstructural characteristics of the carbonated olivine are very important for interpretation of the leaching results.

The chemical composition of the fully carbonated olivine was determined by digestion followed by ICP-MS (for $\mathrm{Al}, \mathrm{Ca}, \mathrm{Cr}, \mathrm{Fe}$, and $\mathrm{Ni}$ ) and by XRF (for $\mathrm{Co}, \mathrm{Mg}, \mathrm{Mn}$, and $\mathrm{Si}$ ). The obtained results, in decreasing order, were: 18.1 wt. \% Mg; 13.8 wt. \% Si; 2.5 wt. \% Fe; 0.19 wt. \% Ni; 0.17 wt. \% Cr; 0.13 wt. $\%$ Ca; 0.11 wt. \% Al; 0.06 wt. \% Mn; 0.01 wt. \% Co. The respective weight percentages are lower compared to fresh olivine (Table 1) due to the conversion of magnesium silicate to magnesium carbonate; the addition of $\mathrm{CO}_{2}$ increases the total mass of the olivine by roughly $50 \%$, thus reducing the elemental concentrations.

The mineralogy of the fully-carbonated olivine was analyzed using XRD; the diffractogram is shown in Figure 1. The magnesium silicate (ferroan-forsterite) that was predominant in fresh olivine (84.5 wt. \%) is now converted nearly completely ( 0.5 wt. \% remaining) to magnesium carbonate (magnesite $\left(\mathrm{MgCO}_{3}\right), 87.0 \mathrm{wt}$ \%). Periclase and brucite are absent, since they easily carbonate and are also converted to magnesite. The various other minerals that were found in fresh olivine are still present in the carbonated olivine, as they either did not react during carbonation or were formed as hydrated by-products of the reaction: clinochlore $(3.7 \mathrm{wt} . \%)$, talc $(3.1 \mathrm{wt} . \%)$, lizardite $(2.3 \mathrm{wt}$ \%), tirodite (1.4 wt. \%), fayalite (0.9 wt. \%), quartz (0.9 wt. \%), magnesian calcite $(0.3$ wt. \%), and chromite (0.2 wt. \%). Hydrated silicates are known to require dehydroxylation to enable accelerated carbonation [24], and fayalite is known to require elevated pressures to convert into siderite [25]. 
The particle size distribution of the fully-carbonated olivine can be seen in Figure 4. The average particle size is considerably lower after carbonation as $90 \mathrm{vol} . \%$ of the carbonated olivine has a particle size below $42 \mu \mathrm{m}$. The BET specific surface area increased from $0.49 \mathrm{~m}^{2} / \mathrm{g}$ to $16.1 \mathrm{~m}^{2} / \mathrm{g}$. This confirms that carbonation can act as a substitute to more intense comminution of fresh olivine. Two distinctive peaks can clearly be identified in the particle size distribution, with one peak around $5 \mu \mathrm{m}$ and one peak around $30 \mu \mathrm{m}$. The SEM and EDX analyses presented in Figure 5 provide insight into their occurrence. The carbonated olivine consists of small particles that are clusters of small spheres, and larger crystalline particles. The small particles are analyzed to be silica $\left(\mathrm{SiO}_{2}\right)$ rich (Figure 5c), whereas the crystalline particles are primarily magnesium carbonate $\left(\mathrm{MgCO}_{3}\right)$, seemingly in solid-solution with iron carbonate $\left(\mathrm{FeCO}_{3}\right)$ (Figure $5 \mathrm{~b}$ ). The appearance of clustered silica particles is likely due to the aggregation of smaller polymerized silica particles. Surface silica will polymerize setting free a water molecule. The polymerized silica will break off from the surface of the olivine particle forming small silica particles free in solution. These small particles can either grow by further condensation or by aggregating together forming the clusters that are shown in Figure 5c. This reaction mechanism was proposed for the preparation of silica from olivine by Lieftink and Geus [26] and was confirmed by Lazaro et al. [27].

The fully carbonated olivine was analyzed using EPMA to map the concentration of each element within the particles. The concentrations of chromium, iron, magnesium and nickel are shown in Figure 6. Chromium is concentrated in iron-rich particles, in agreement with chromite composition. Iron distribution largely coincides with that of magnesium, confirming the solid-solution carbonate formation $\left(\left(\mathrm{Mg}_{1-x}, \mathrm{Fe}_{x}\right) \mathrm{CO}_{3}\right)$. Nickel appears to be more dispersed throughout the material, although the outline of the carbonate particles can be seen in its map, which would suggest a preference for the carbonate phase. Highly concentrated nickel is also found in a few small particles and the few chromium-rich particles.

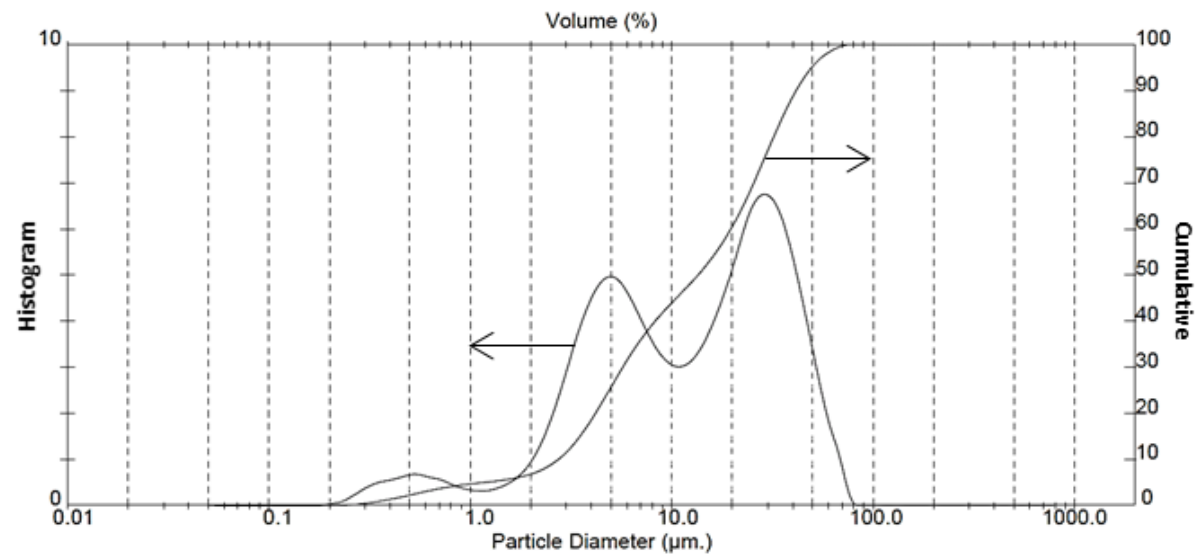

Figure 4. Particle size distribution of fully carbonated olivine, determined by LDA. 
a)
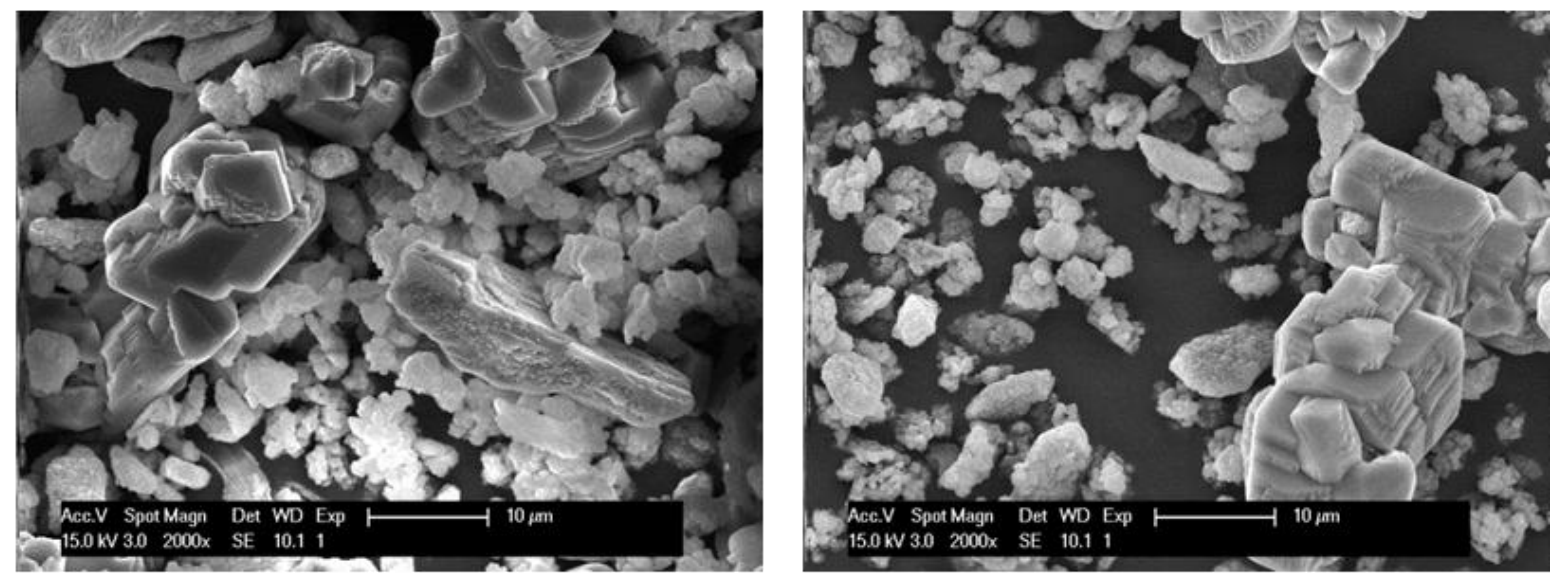

b)
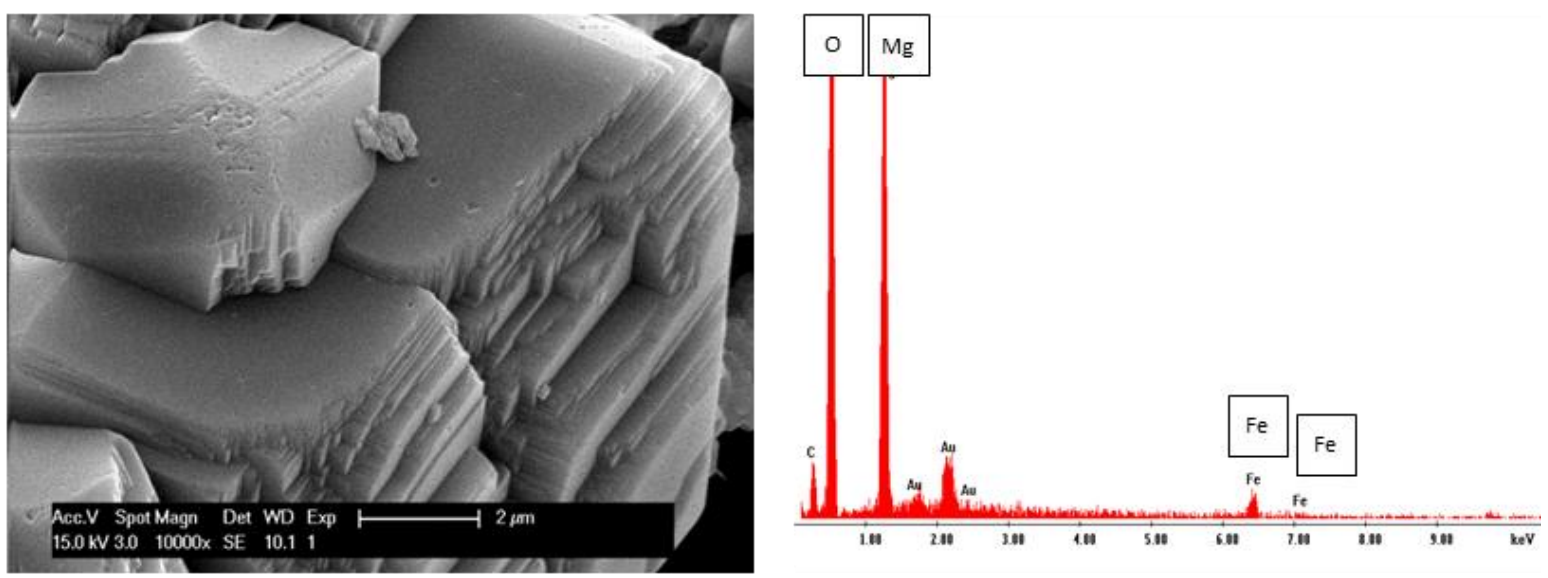

c)
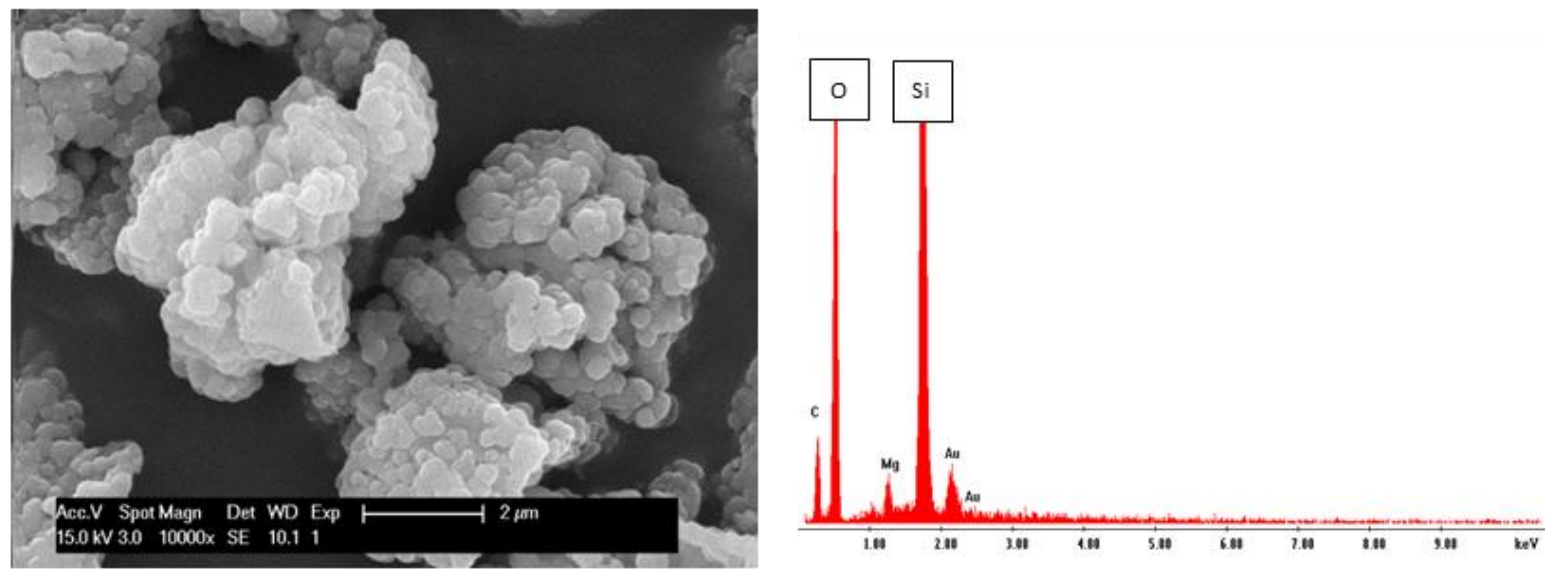

Figure 5. SEM and EDX analyses of individual fully carbonated olivine particles: (a) fully carbonated olivine at low magnification; (b) ferro-magnesite crystal; (c) colloidal silica cluster. Note that $\mathrm{Au}$ and $\mathrm{C}$ signals are also attributable to gold coating and carbon tape. 


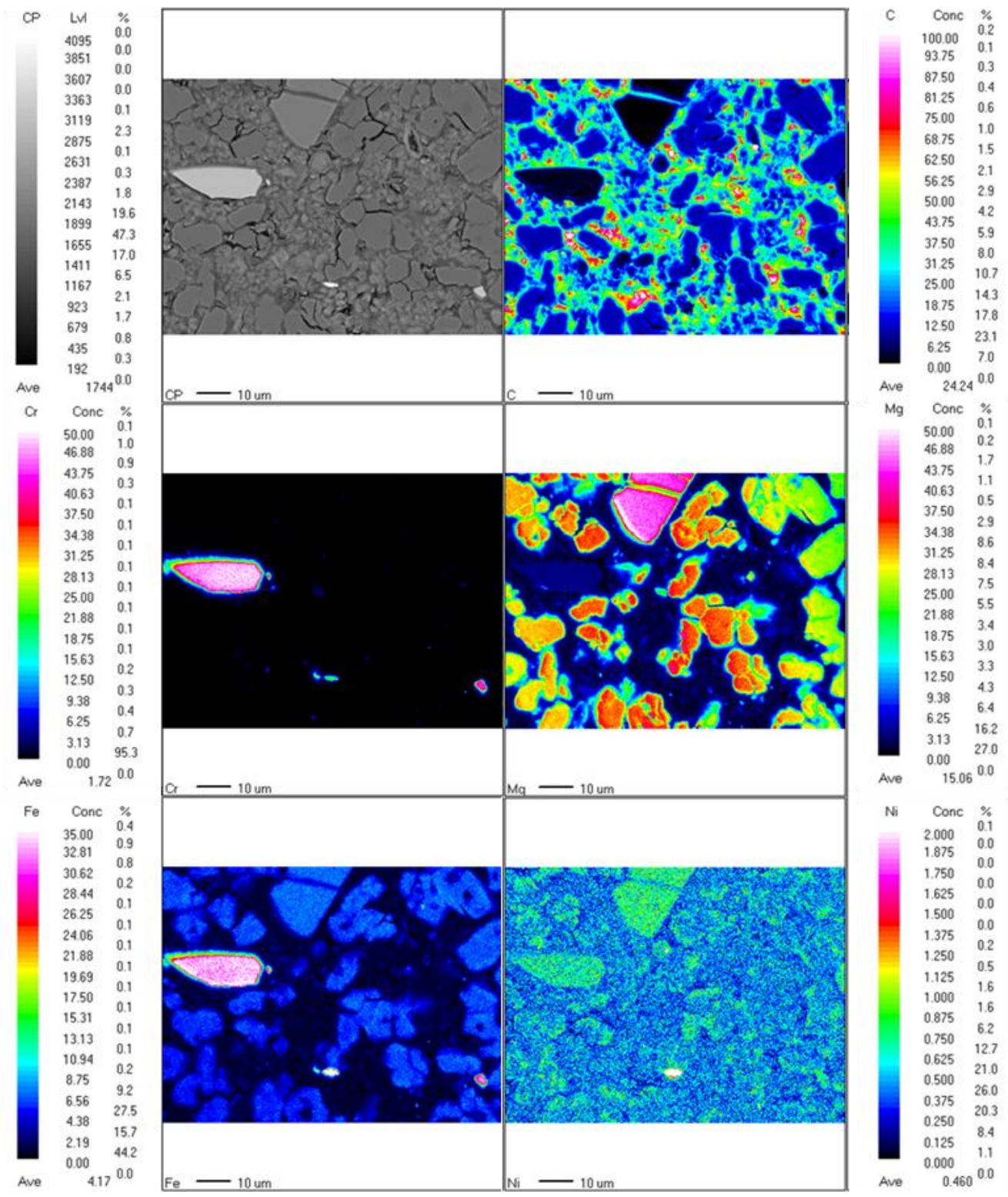

Figure 6. Backscattered scanning electron image and elemental concentration mapping (carbon, chromium, magnesium, iron and nickel) of fully carbonated olivine, captured by EPMA; concentration scale is relative to max/min levels; color gradient in $\mathrm{Mg}$ map is due to curvature artifact that occurs at these relatively low magnifications.

Additional elemental distributions are mapped in Figures 7 and S8, taken at slightly lower magnification of another area of the embedded sample. In Figure 7 it is seen that silicon is present in regions poor in magnesium and iron, which supports the EDX results (Figure 5) in that silicon forms distinct particles separate from the carbonate phase. The few calcium-rich particles have magnesium, silicon, and aluminum co-present (Figure 7), and low levels of carbon (Figure S8), which could indicate a calcium-magnesium-aluminum silicate originally present in the olivine or formed during the reaction. A possible natural analogue would be alumoåkermanite $\left((\mathrm{Ca}, \mathrm{Na})_{2}\left(\mathrm{Al}, \mathrm{Mg}, \mathrm{Fe}^{2+}\right)\left(\mathrm{Si}_{2} \mathrm{O}_{7}\right)\right)[28]$. 


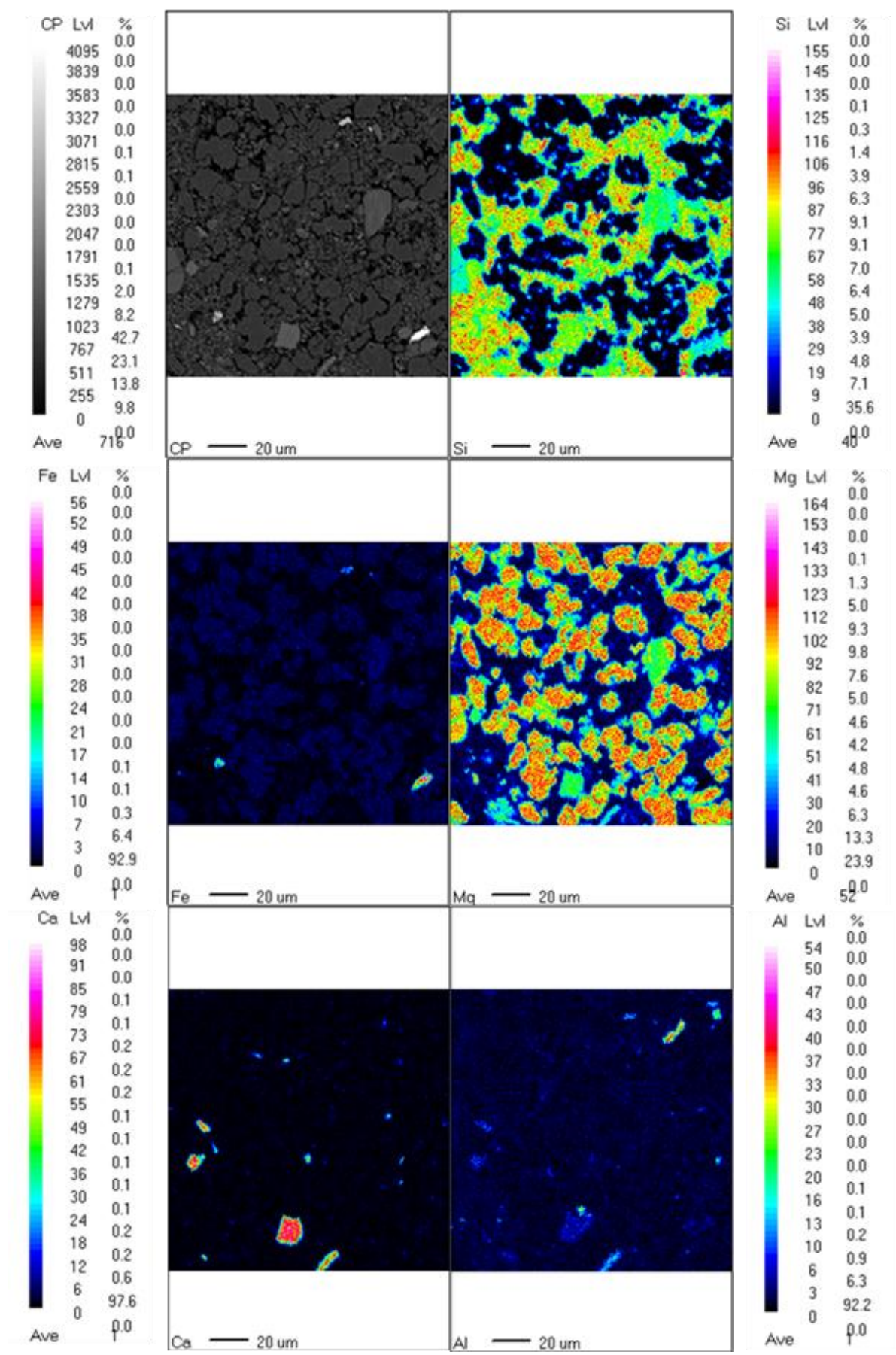

Figure 7. Backscattered scanning electron image and elemental concentration mapping (silicon, iron, magnesium, calcium and aluminum) of fully carbonated olivine, captured by EPMA; color scale indicates max/min levels.

Spot EPMA analysis on certain regions of the polished sample is shown in Figure 8, with their chemical compositions given in Table 3 . The four analyzed spot areas are very distinctive. Area 001 is a chromium- and iron-concentrated chromite particle. Area 002 contains mainly a combination of magnesium and silicon, meaning it is a rare grain of unreacted ferroan-forsterite. Area 003 contains magnesium, iron and carbon, indicative of ferro-magnesite $\left(\left(\mathrm{Mg}_{1-x}, \mathrm{Fe}_{x}\right) \mathrm{CO}_{3}\right)$. Area 004 is a polymerized silica cluster, as it contains high concentrations of silicon, low concentrations of magnesium and carbon that originates from the embedding resin that penetrates the gaps between the small agglomerated silica 
particles. These results reaffirm the EDX analysis presented in Figure 5, indicating that carbonate and silica phases (as well as unreacted mineral grains) form distinct particles in the product powder. This means that these particles may be separable by physical means, in view of producing high-value product streams.

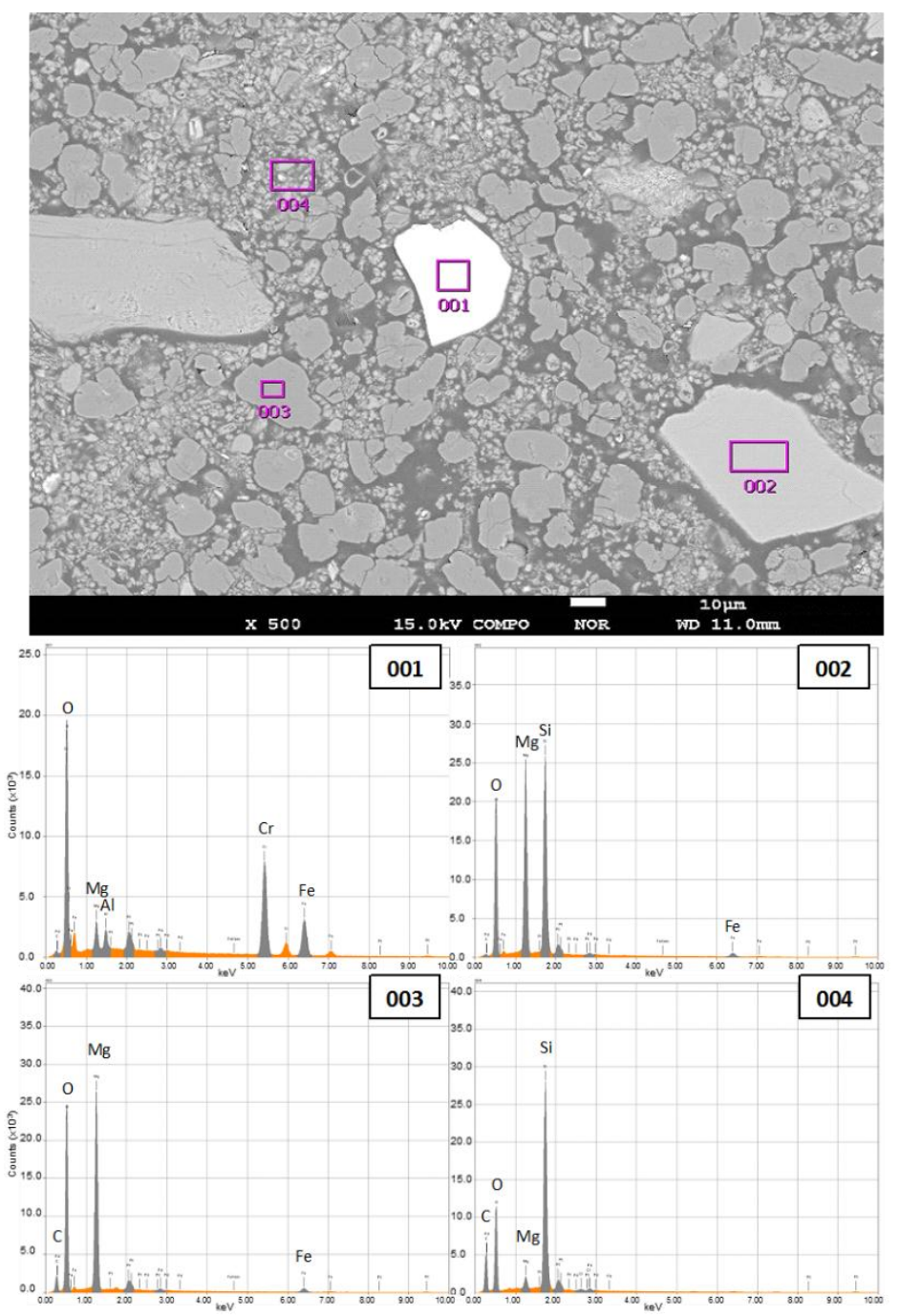

Figure 8. Backscattered scanning electron image of fully carbonated olivine and EPMA scanning of selected areas; mounted sample was coated with platinum and palladium for the analysis.

Table 3. Chemical composition (\%), determined by EPMA, of spot areas in Figure 8; carbon as elemental $\mathrm{C}$ and other elements as oxides.

\begin{tabular}{ccccc}
\hline Chemical Formula & $\mathbf{0 0 1}$ & $\mathbf{0 0 2}$ & $\mathbf{0 0 3}$ & $\mathbf{0 0 4}$ \\
\hline $\mathrm{C}$ & 0.5 & 1.2 & 19.8 & 37.7 \\
$\mathrm{MgO}$ & 4.8 & 35.3 & 68.6 & 2.6 \\
$\mathrm{SiO}_{2}$ & 0 & 57.6 & 0 & 59.8 \\
$\mathrm{Al}_{2} \mathrm{O}_{3}$ & 3.3 & 0 & 0 & 0 \\
$\mathrm{Cr}_{2} \mathrm{O}_{3}$ & 55.5 & 5.8 & 0 & 0 \\
$\mathrm{Fe}_{2} \mathrm{O}_{3}$ & 35.9 & 0 & 11.6 & 0 \\
\hline
\end{tabular}




\subsection{Acid Leaching of Fresh and Carbonated Olivine}

\subsubsection{Inorganic Acids}

Limited research mentions the acid leaching of nickel from olivine. Our own experiments have two main objectives. The first objective is to look at the leaching behavior of various inorganic and organic acids for olivine. The second objective is to investigate the impact of carbonation as a pre-treatment step to leaching.

The metal extractions for the leaching from fresh and carbonated olivine with the three inorganic acids tested can be seen in Figure 9. Sanemasa et al. [29] found that there is no preferential leaching of the silicate structure in olivine of one metal over the other. Our results, both for fresh as well as carbonated olivine, confirm these findings: for each acid, at the various concentrations, there is no preferential leaching of magnesium, iron or nickel. In all cases, chromium leaching was minimal, which confirms that it is located in different particles than the ones containing nickel, and that those chromium-containing particles do not undergo dissolution during leaching, while the ones containing nickel do.

Terry et al. [30] noted that olivine dissolves congruently, meaning a complete breakdown of the silicate structure to give, percentage-wise, the same amount of silica and metal cation leached. The leaching results for fresh olivine in Figure 9 do not entirely confirm these findings. It seems that less silica is solubilized than would be expected based on a congruent dissolution. This indicates that dissolved silica will precipitate, possibly by forming a silica gel. Notably, the results for carbonated olivine (Figure 9b,d,f) show substantially less leaching of silica compared to fresh olivine. This occurs because the metal silicates in the fresh olivine are transformed to metal carbonates in carbonated olivine. Carbon dioxide will now be released instead of silica during the acid leaching. The polymerized silica in the carbonated olivine does not significantly partake in the dissolution reactions of the acid attack.

Increasing the acid concentration enhances the leaching of most elements. The leaching of $\mathrm{Mg}, \mathrm{Fe}$ and $\mathrm{Ni}$ from fresh olivine increased from below $10 \%$ at $0.02 \mathrm{~N}$ to above $60 \%$ at $2.56 \mathrm{~N}$ for all inorganic acids tested. This impact was even more apparent for the leaching of carbonated olivine with $\mathrm{HCl}$ and $\mathrm{HNO}_{3}$, where $\mathrm{Mg}, \mathrm{Fe}$, and $\mathrm{Ni}$ extractions increased from below $10 \%$ at $0.02 \mathrm{~N}$ to nearly $100 \%$ at $2.56 \mathrm{~N}$. Most notably, the leaching of nickel from carbonated olivine is substantially better than from fresh olivine when using hydrochloric and nitric acids. A concentration of $2.56 \mathrm{~N}$ of either acid leaches, respectively, $100 \%$ and $91 \%$ of nickel from carbonated olivine. For fresh olivine these values are only $66 \%$ and $64 \%$, respectively.

In terms of the differences between the three acids, all three inorganic acids show similar leaching behavior of fresh olivine for the same acid normalities. Between $60 \%$ and $70 \%$ of $\mathrm{Mg}, \mathrm{Fe}$ and $\mathrm{Ni}$ is leached with $2.56 \mathrm{~N}$ of either $\mathrm{HCl}, \mathrm{H}_{2} \mathrm{SO}_{4}$ or $\mathrm{HNO}_{3}$. At intermediate normalities, sulfuric acid performed better; Sanemasa et al. [29] explain that sulfate is better at stabilizing the metal cations than the chloride anions. For carbonated olivine, however, there is a clear and opposite distinction between the leaching behaviors of nitric and hydrochloric acid compared to sulfuric acid. $\mathrm{H}_{2} \mathrm{SO}_{4}$ leaches substantially less $\mathrm{Mg}, \mathrm{Fe}$ and $\mathrm{Ni}$ than $\mathrm{HCl}$ and $\mathrm{HNO}_{3}$. Whereas $\mathrm{H}_{2} \mathrm{SO}_{4}$ leaches only about $30 \% \mathrm{Mg}, \mathrm{Fe}$ and $\mathrm{Ni}$ at $2.56 \mathrm{~N}$, for $\mathrm{HCl}$ and $\mathrm{HNO}_{3}$ this is equal to about $90 \%$ to $100 \%$. Additional leaching tests, discussed later on, were performed to investigate this phenomenon. 

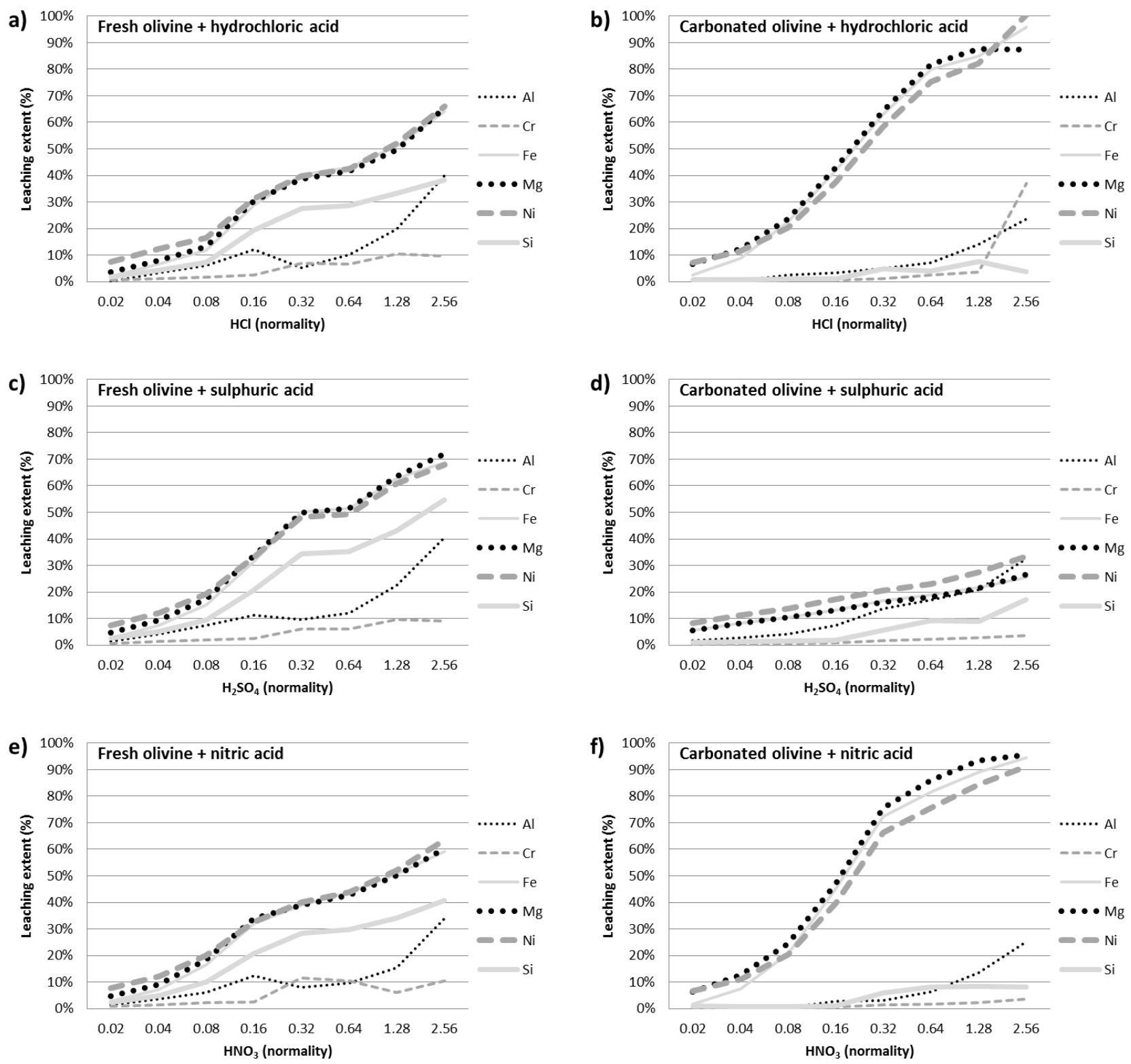

Figure 9. Leaching extent from fresh $(\mathbf{a}, \mathbf{c}, \mathbf{e})$ and carbonated $(\mathbf{b}, \mathbf{d}, \mathbf{f})$ olivine with hydrochloric $(\mathbf{a}, \mathbf{b})$, sulfuric (c,d) and nitric (e,f) acids; Tables S2 and S3 provide statistical data on replicates.

The leaching enhancement ratio of nickel from carbonated olivine compared to fresh olivine can be seen in Table 4; the enhancement ratio $(\varphi)$ is calculated as the percent of nickel leached from carbonated olivine $\left(\chi_{\mathrm{Ni}, \mathrm{carb}}\right)$ over the percent of nickel leached from fresh olivine $\left(\chi_{\mathrm{Ni}, \text { fresh }}\right): \varphi=\chi_{\mathrm{Ni}, \text { carb }} / \chi_{\mathrm{Ni}, \text { fresh }}$. For $\mathrm{HCl}$ and $\mathrm{HNO}_{3}$, the leaching ratio increases with increasing acid concentration, peaking at $0.64 \mathrm{~N}$, where carbonated olivine leaches, respectively, 1.77 and 1.72 times better than fresh olivine. The slight decrease at even higher concentrations can be attributed to the fact that the leaching of carbonated olivine is approaching completion, while fresh olivine still benefits significantly from higher acid concentrations (Figure 9). For $\mathrm{H}_{2} \mathrm{SO}_{4}$, the leaching of carbonated olivine compared to fresh olivine follows the opposite path, decreasing with increasing acid concentrations. This indicates that the inhibiting effect of $\mathrm{H}_{2} \mathrm{SO}_{4}$ is dependent on the sulfate ion concentration. The leaching ratio for $\mathrm{H}_{2} \mathrm{SO}_{4}$ reaches a minimum at $0.32 \mathrm{~N}$ with only 0.42 times the percentage of nickel extracted from carbonated olivine compared to fresh olivine. 
Table 4. Nickel leaching enhancement ratios of carbonated olivine over fresh olivine for inorganic and organic acids.

\begin{tabular}{cccccccc}
\hline $\begin{array}{c}\text { Leaching Ratio } \boldsymbol{\varphi} \\
\text { (Carbonated/Fresh) }\end{array}$ & $\mathbf{H C l}$ & $\mathbf{H N O}_{3}$ & $\mathbf{H}_{2} \mathbf{S O}_{\mathbf{4}}$ & $\begin{array}{c}\text { Leaching Ratio } \boldsymbol{\varphi} \\
\text { (Carbonated/Fresh) }\end{array}$ & Lactic & Citric & Formic \\
\hline $0.02 \mathrm{~N}$ & 0.99 & 0.85 & 1.11 & $0.25 \mathrm{~N}$ & 1.01 & 1.15 & 0.46 \\
$0.04 \mathrm{~N}$ & 0.93 & 0.92 & 0.92 & $0.5 \mathrm{~N}$ & 1.18 & 1.25 & 0.46 \\
$0.08 \mathrm{~N}$ & 1.23 & 1.01 & 0.72 & $1.0 \mathrm{~N}$ & 1.38 & 1.16 & 0.47 \\
$0.16 \mathrm{~N}$ & 1.20 & 1.22 & 0.52 & $2.0 \mathrm{~N}$ & 1.48 & 1.00 & 0.57 \\
$0.32 \mathrm{~N}$ & 1.47 & 1.65 & 0.42 & $4.0 \mathrm{~N} *$ & 1.35 & - & 0.68 \\
$0.64 \mathrm{~N}$ & 1.77 & 1.72 & 0.47 & & & & \\
$1.28 \mathrm{~N}$ & 1.58 & 1.62 & 0.45 & & & & \\
$2.56 \mathrm{~N}$ & 1.52 & 1.43 & 0.49 & & & &
\end{tabular}

\subsubsection{Organic Acids}

The metal extractions from fresh and carbonated olivine by the three organic acids tested are shown in Figure 10. Some similar conclusions can be drawn as for inorganic acids. There is also essentially no preferential dissolution of $\mathrm{Mg}, \mathrm{Fe}$ and $\mathrm{Ni}$ both from fresh and carbonated olivine. Although there is also less silica in solution as would be expected based on a congruent dissolution of the fresh olivine silicate structure, this difference is less than for inorganic acids. Silica is, thus, less prone to precipitation in the presence of organic acids, but is equally insoluble when already precipitated as colloidal silica in the case of carbonated olivine.

The leaching enhancement ratio for lactic acid increases with increasing acid concentrations, reaching a maximum of 1.48 at $2 \mathrm{~N}$ (Table 4). Contrary to lactic and formic acids, leaching with citric acid remains constant (for fresh olivine), or decreases slightly (for carbonated olivine) with increasing acid concentration (Figure 10). The enhancement ratio remains above one up to $1 \mathrm{~N}$, with a maximum of 1.25 at $0.5 \mathrm{~N}$ (Table 4). Citrate ions act as chelating agents and will form strong metal-ligand complexes that enhance leaching. It appears that due to these highly soluble complexes, citric acid already reaches its maximum leaching potential at low concentrations. Tzeferis et al. [31] also found that increasing the citric acid concentration from $0.5 \mathrm{M}$ to $1.5 \mathrm{M}$ did not increase the nickel or iron extraction from nickeliferous ores at low pulp densities. At higher pulp densities, the percentages of nickel and iron leached at $0.5 \mathrm{M}$ were substantially lower than for low pulp densities, and they did increase when the citric acid concentration was increased to $1.5 \mathrm{M}$. This confirms the idea that citric acid has an intrinsic maximum for the leaching of metals or specific ores, which, once reached, will not increase further when increasing the citric acid concentration.

Comparing the leaching results from fresh olivine with carbonated olivine, it can be seen that there is also a large discrepancy among the organic acids (Table 4). Nickel leaching by citric and lactic acids is enhanced when olivine is carbonated (i.e., enhancement ratios > 1). Leaching by formic acid, however, just like with sulfuric acid, experiences a considerable decrease $(-32 \%$ to $-54 \%)$ in nickel extraction from carbonated olivine compared to fresh olivine. 

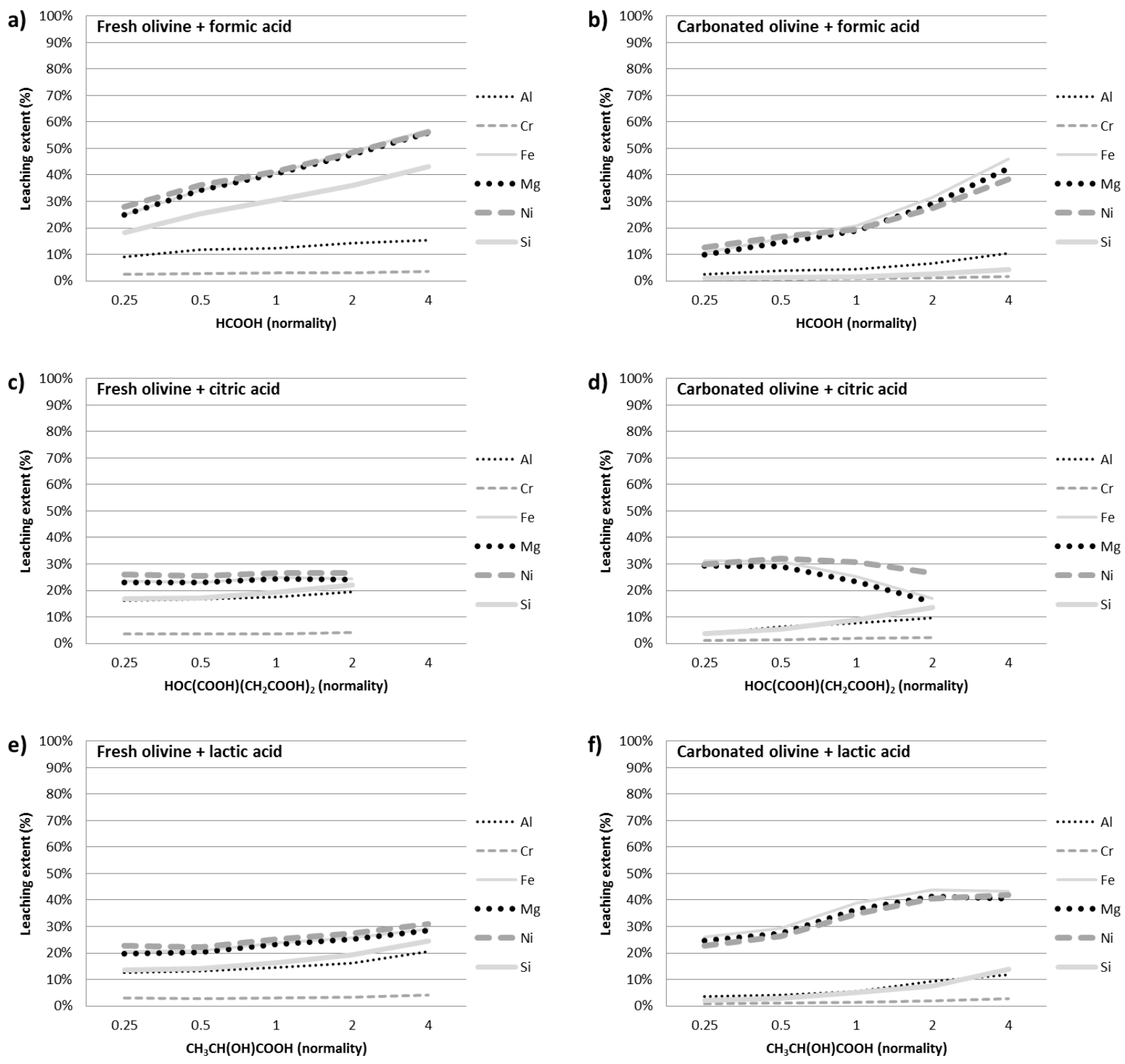

Figure 10. Leaching extent from fresh (a,c,e) and carbonated (b,d,f) olivine with formic (a,b), citric (c,d), and lactic (e,f) acids; Tables S4 and S5 provides statistical data on replicates.

\subsubsection{Sulfuric Acid Leaching Investigation}

Aforementioned results for fresh olivine show a limited leaching of nickel, magnesium and iron (the cationic components of ferroan-forsterite) with $\mathrm{H}_{2} \mathrm{SO}_{4}$ compared to $\mathrm{HCl}$ and $\mathrm{HNO}_{3}$. Terry et al. [30] noted that sulfate ions form stronger metal cation-acid anion complexes than chloride ions, which would lead to an increased reactivity with sulfuric acid. For carbonated olivine, however, this is completely reversed and thus does not follow the existing theory. One possibility is that the sulfate ions form insoluble compounds with the components of carbonated olivine (carbonate and silica phases), passivating the particles. To test this hypothesis, leaching tests were conducted using sulfuric acid and mineral mixtures. The mineral mixtures consisted of one or more of the following components: pure magnesite $\left(\mathrm{MgCO}_{3}\right)$, pure fumed (amorphous) silica $\left(\mathrm{SiO}_{2}\right)$, fresh olivine and fully carbonated olivine. 
If the carbonation products (magnesite and silica) had unexpected behavior in contact with sulfuric acid, these tests would help uncover these effects. Since the pure phases did not contain nickel or iron, leaching data for magnesium was collected.

Figure 11 presents the data on magnesium leaching from the pure components (Figure 11a) and from the mineral mixtures (Figure 11c). Figure 11a presents the raw leaching data (expressed as $\mathrm{g}$, $\mathrm{Mg} / 100 \mathrm{~mL}$ ) and the data expressed as a percentage of the theoretical maximum leaching extent (based on $\mathrm{Mg}$ content in the mineral: $0.577 \mathrm{~g}, \mathrm{Mg} / 100 \mathrm{~mL}$ for pure $\mathrm{MgCO}_{3}, 0.543 \mathrm{~g}, \mathrm{Mg} / 100 \mathrm{~mL}$ for fresh olivine, and $0.362 \mathrm{~g}, \mathrm{Mg} / 100 \mathrm{~mL}$ for fully carbonated olivine). It is found that pure $\mathrm{MgCO}_{3}$ leaches completely in $1.28 \mathrm{~N} \mathrm{H}_{2} \mathrm{SO}_{4}$, so there is no negative effect of sulfate anions, and no precipitation of insoluble compound. In the case of olivine, leaching is much more extensive in the case of fresh olivine (77\%) compared to fully carbonated olivine (20\%). This confirms the effects seen in previous results (Figure 9). Figure $11 \mathrm{~b}$ presents kinetic data on the leaching of fresh and fully carbonated olivine by $1.28 \mathrm{~N} \mathrm{H}_{2} \mathrm{SO}_{4}$. Leaching of the latter is slower and stalls after two hours, while leaching of the former continuously increases over time, although it is also relatively slow (leaching after $2 \mathrm{~h}$ is less than a third that after $24 \mathrm{~h}$ ).

Figure 11c presents the leaching results of four mineral mixtures. For each mixture, data is presented in raw format $(\mathrm{g}, \mathrm{Mg} / 100 \mathrm{~mL})$ and as a percentage of the theoretical maximum leaching based on the mixture's composition and the leaching results obtained for the singular components (Figure 11a). The first mixture contains only the pure minerals, and shows that $\mathrm{SiO}_{2}$ does not prevent leaching of $\mathrm{MgCO}_{3}$, as the leaching extent reaches $97 \%$ of the predicted value (i.e., within experimental uncertainty). The second mixture shows that $\mathrm{MgCO}_{3}$ does not alter the leaching of fresh olivine, as the leaching extent is equal to the predicted value; hence, no insoluble precipitate forms. Likewise, the third mixture shows that $\mathrm{SiO}_{2}$ does not alter the leaching of fresh olivine (the value greater than $100 \%$ is within experimental uncertainty); again, no insoluble precipitate forms. Finally, the last mixture shows that carbonated olivine still leaches poorly and that leaching of $\mathrm{MgCO}_{3}$ is not affected by the presence of carbonated olivine, since the leaching extent is approximately equal to the calculated prediction (97\%). This last mixture result shows that no component of carbonated olivine prevents the leaching of pure $\mathrm{MgCO}_{3}$, although the ferro-magnesite present in carbonated olivine is affected.

To better understand what happens with the sulfuric acid-leached carbonated olivine, the leaching residue was characterized by XRD, and results are shown in Figure 1. The diffraction pattern of the leaching residue is very similar to that of the pre-leaching fully carbonated olivine. No additional peaks form after leaching, which indicates that no crystalline precipitates form. Additionally, all significant peaks present in the pre-leaching mineral (attributable to magnesite) are still present after leaching, meaning that magnesite leaching is not extensive, as the magnesium leaching data indicated (Figure 11a). The main difference seen between the two diffractograms is that the leached residue has a larger "bump", which is attributable to a quasi-amorphous phase. Since this bump is near the theoretical location for crystalline silica (i.e., quartz), it is possible to infer that it represents the colloidal silica content of the material (and hence is also present in the pre-leached mineral). The reason why the bump grows after leaching, is that the crystalline content is reduced, due to partial dissolution of magnesite. These XRD results suggest that no precipitate forms after leaching, either crystalline or quasi-amorphous in nature. 


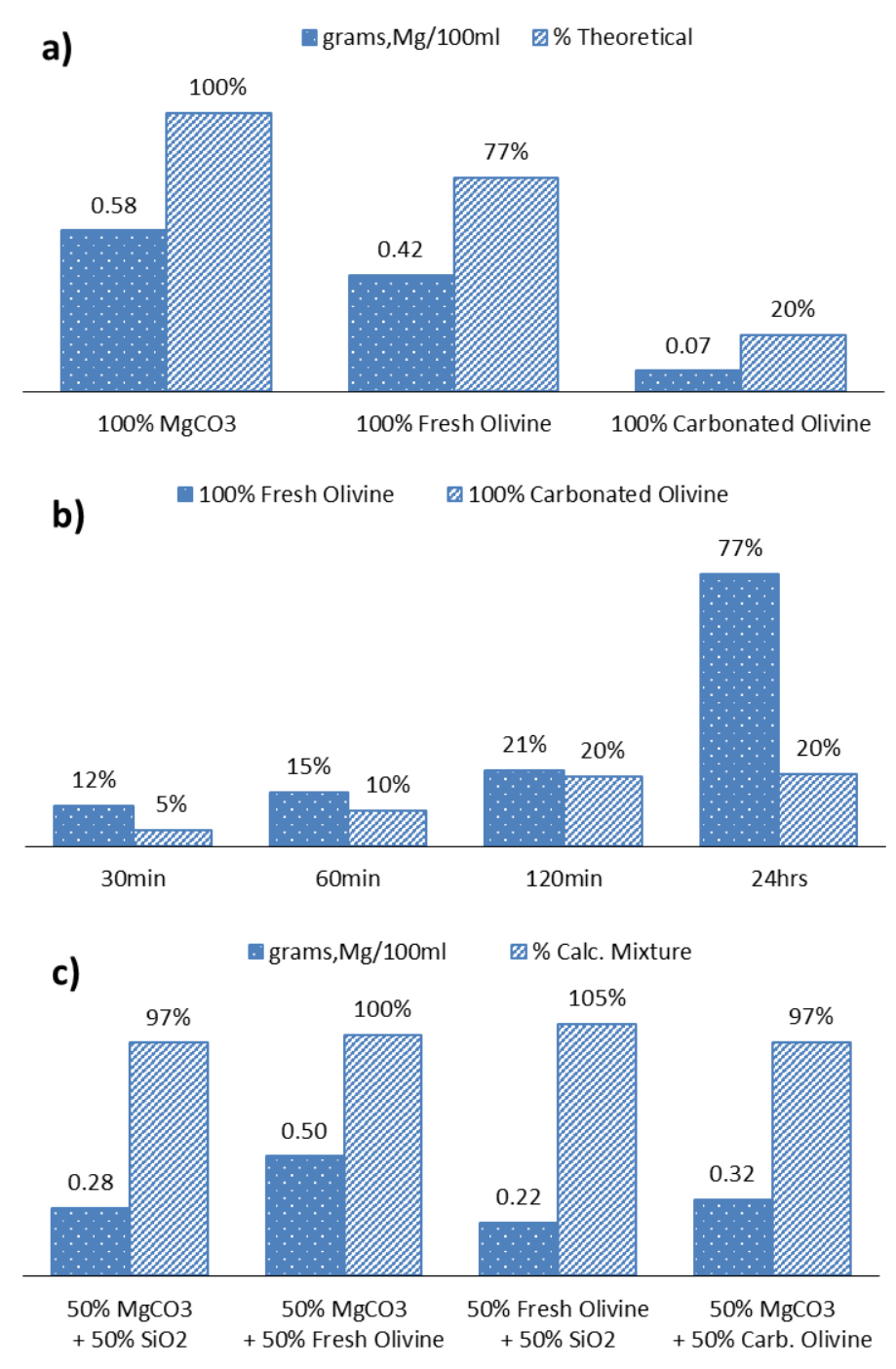

Figure 11. (a) leaching extent (in $1.28 \mathrm{~N} \mathrm{H}_{2} \mathrm{SO}_{4}, 2 \mathrm{~g} / 100 \mathrm{~mL}, 24 \mathrm{~h}$ ) from pure magnesium carbonate, fresh olivine and carbonated olivine; (b) leaching extent (in $1.28 \mathrm{~N} \mathrm{H}_{2} \mathrm{SO}_{4}$, $2 \mathrm{~g} / 100 \mathrm{~mL}$ ) from fresh olivine and carbonated olivine as a function of time; (c) leaching extent (in $1.28 \mathrm{~N} \mathrm{H}_{2} \mathrm{SO}_{4}, 2 \mathrm{~g} / 100 \mathrm{~mL}, 24 \mathrm{~h}$ ) from mixtures of pure magnesium carbonate, pure silica, fresh olivine and carbonated olivine.

Based on leaching and XRD results, it appears that the only explanation for the poor leaching results of fully carbonated olivine in sulfuric acid is that the magnesite present in carbonated olivine is a solid-solution of $\mathrm{MgCO}_{3}$ and $\mathrm{FeCO}_{3}$. Since pure $\mathrm{MgCO}_{3}$ leaches adequately in sulfuric acid, and amorphous silica does not affect leaching, it could be that the iron content of the ferro-magnesite helps to passivate the mineral particles after an initial limited leaching extent. Further research is needed to characterize this mechanism.

\section{Conclusions}

The increasing demand and diminishing availability of raw materials requires us to look beyond conventional sources. In the future, the importance of low-grade ores and waste streams as a source for raw materials will only increase. The objective of this work was to look at the extraction of nickel from 
a low-grade silicate ore, namely olivine. This was achieved by combining conventional acid leaching with a pre-treatment step in which the olivine underwent mineral carbonation. It is anticipated that the mineral carbonation pre-treatment approach may also be applicable to other ultrabasic and lateritic ores.

In a first processing step, olivine was fully carbonated at high $\mathrm{CO}_{2}$ partial pressures (35 bar) and optimal temperature $\left(200{ }^{\circ} \mathrm{C}\right)$ with the addition of $\mathrm{pH}$ buffering agents. Although substantial research has looked into the carbonation of olivine, reported extents of carbonation are usually lower than those achieved in this work (i.e., full carbonation). The carbonation increased linearly with time, indicating that carbonation is not limited by the formation of a passivating silica layer under the processing conditions used. This was confirmed by SEM analysis of partially carbonated olivine, showing that after carbonation distinct crystalline magnesium carbonate particles and clusters of nano-silica are formed. High solids loading and mixing rate appear to enhance the carbonation reaction substantially due to the olivine particles being eroded by increased particle collisions. Using electron probe micro analysis it was possible to map the distribution of both major (C, Mg, Si) and minor ( $\mathrm{Al}, \mathrm{Ca}, \mathrm{Cr}, \mathrm{Fe}, \mathrm{Ni}$ ) elemental components in this material. The main products of the carbonation reaction included quasi-amorphous colloidal silica, chromium-rich metallic particles, and ferro-magnesite.

The second stage of this work looked at the extraction of nickel and other metals by leaching fresh as well as carbonated olivine with an array of inorganic and organic acids to test their leaching efficiency. Compared to leaching from untreated olivine, the percentage of nickel extracted from carbonated olivine by acid leaching was significantly increased. For example, using $2.6 \mathrm{~N} \mathrm{HCl}$ and $\mathrm{HNO}_{3}, 100 \%$ and $91 \%$ of nickel was respectively leached from carbonated olivine. This compares to only $66 \%$ and $64 \%$ nickel leached from untreated olivine using the same acids. Similar trends were observed with the organic acids used, where the leaching enhancement reached a factor of 1.25 using $0.5 \mathrm{~N}$ citric acid, and a factor of 1.48 using $2 \mathrm{~N}$ lactic acid. It was found that two acids, sulfuric and formic, are unsuitable for leaching of carbonated olivine.

Looking at future developments, it should be pointed out that in the present work the metal extraction was performed after carbonation. Selective metal recovery of the olivine during carbonation might substantially enhance the leaching and reduce extractant consumption. During carbonation, the metals dissolve due to the acidic aqueous solution as a result of carbonic acid formation. The residual solids could then be separated at high temperatures and pressures prior to exiting the reactor, producing a purified silica stream and a concentrated metal liquor or metal precipitate. Another option is to separate the final products (i.e., silica-rich clusters, carbonate crystals, and metallic particles) prior to leaching, and leach only the metal-rich fraction; this may reduce the amount of sequestered $\mathrm{CO}_{2}$ liberation. Lastly, re-use of any $\mathrm{CO}_{2}$ released during acidification can contribute to lowering processing costs associated with $\mathrm{CO}_{2}$ concentration from industrial emission sources. These processes are presently in development using the proprietary reactor technology of Innovation Concepts B.V. called the " $\mathrm{CO}_{2}$ Energy Reactor" [13]. This reactor makes use of a Gravity Pressure Vessel (GPV) that supports hydrostatically built supercritical pressures, runs in autothermal regime by recycling the exothermic carbonation heat, and operates under turbulent three-phase plug flow configuration. This reactor is expected to allow faster carbonation conversion and more economical processing. 


\section{Acknowledgments}

The KU Leuven Industrial Research Fund (IOF) is gratefully acknowledged for funding the Knowledge Platform on Sustainable Materialization of Residues from Thermal Processes into Products $\left(\right.$ SMaRT-Pro $\left.^{2}\right)$ in which this work was performed. Rafael Santos is thankful for the PGS-D support from the Natural Sciences and Engineering Research Council of Canada (NSERC), and for postdoctoral financial support (PDM) from the KU Leuven Special Research Fund (BOF). The EPMA work was made possible due to the support of the Hercules Foundation (project ZW09-09). The KU Leuven Department of Earth and Environmental Sciences is acknowledged for the use of XRD and LDA equipment.

\section{Author Contributions}

Rafael M. Santos conceptualized and managed the research, co-supervised the Master student, characterized materials and samples, and co-wrote the paper. Aldo Van Audenaerde performed experiments, analyzed the data and co-wrote the paper. Yi Wai Chiang co-supervised the Master student, performed BET analyses and co-wrote the paper. Remus I. Iacobescu performed EPMA analyses and co-wrote the paper. Pol Knops conceptualized the research and provided industrial advice. Tom Van Gerven supervised the personnel, provided funding and managed the laboratory facilities.

\section{Conflicts of Interest}

The authors declare no conflict of interest.

\section{References}

1. Goldie, R.J. The shortage of nickel. Prospectors \& Developers Association of Canada 2004 Convention. Available online: http://www.webcitation.org/query?url=http\%3A\%2F\%2Fwww. pdac.ca $\% 2$ Fdocs $\% 2$ Fdefault-source $\% 2 F$ publications---papers-presentations---conventions $\% 2$ Ftechprgm-goldie.pdf\%3Fsfvrsn\%3D4\&date=2015-07-26 (accessed on 26 July 2015).

2. Kerfoot, D.G.E. Nickel. In Ullmann's Encyclopedia of Industrial Chemistry; Wiley-VCH Verlag GmbH \& Co. KGaA: Weinheim, Germany, 2012; Volume 27, pp. 37-101.

3. McDonald, R.G.; Whittington, B.I. Atmospheric acid leaching of nickel laterites review-Part I: sulphuric acid technologies. Hydrometallurgy 2008, 91, 35-55.

4. Zhai, Y.-C.; Mu, W.-N.; Liu, Y.; Xu, Q. A green process for recovering nickel from nickeliferous laterite ores. Trans. Nonferrous Metals Soc. China 2010, 20, s65-s70.

5. Chen, N.; Cao, Z.-F.; Zhong, H.; Fan, F.; Qiu, P.; Wang, M.-M. A novel approach for recovery of nickel and iron from nickel laterite ore. Metall. Res. Technol. 2015, 112, 306.

6. Harben, P.W.; Smith, C., Jr. Olivine. In Industrial Minerals \& Rocks: Commodities, Markets, and Uses, 7th ed.; Kogel, J.E., Trivedi, N.C., Barker, J.M., Krukowski, S.T., Eds.; Society for Mining, Metallurgy and Exploration, Inc.: Littleton, CO, USA, 2006; pp. 679-684.

7. Smyth, J.R.; Frost, D.J.; Nestola, F.; Holl, C.M.; Bromiley, G. Olivine hydration in the deep upper mantle: Effects of temperature and silica activity. Geophys. Res. Lett. 2006, doi:10.1029/2006GL026194. 
8. Agatzini-Leonardou, S.; Dimaki, D. Heap Leaching of Poor Nickel Laterites by Sulphuric Acid at Ambient Temperature. In Hydrometallurgy '94; Springer: Dordrecht, The Netherlands, 1994; pp. 193-208.

9. Bodor, M.; Santos, R.M.; van Gerven, T.; Vlad, M. Recent developments and perspectives on the treatment of industrial wastes by mineral carbonation-A review. Cent. Eur. J. Eng. 2013, 3, 566-584.

10. Sanna, A.; Hall, M.R.; Maroto-Valer, M. Post-processing pathways in carbon capture and storage by mineral carbonation (CCSM) towards the introduction of carbon neutral materials. Energy Environ. Sci. 2012, 5, 7781-7796.

11. Ahmad, W. Nickel laterites-Fundamentals of chemistry, mineralogy, weathering processes, formation, and exploration. VALE Inco-VITSL. Available online: http:/www.scribd.com/doc/ 83755762/Nickel-Laterites-Vale-Inco-Oct-2008 (accessed on 7 July 2012).

12. Thompson, J.F.H.; Barnes, S.J.; Dyke, J.M. The distribution of nickel and iron between olivine and magmatic sulfides in some natural assemblages. Can. Miner. 1984, 22, 55-66.

13. Santos, R.M.; Verbeeck, W.; Knops, P.; Rijnsburger, K.; Pontikes, Y.; van Gerven, T. Integrated mineral carbonation reactor technology for sustainable carbon dioxide sequestration: " $\mathrm{CO}_{2}$ energy reactor". Energy Proc. 2013, 37, 5884-5891.

14. Gadikota, G.; Matter, J.; Kelemen, P.; Park, A.-H.A. Chemical and morphological changes during olivine carbonation for $\mathrm{CO}_{2}$ storage in the presence of $\mathrm{NaCl}$ and $\mathrm{NaHCO}_{3}$. Phys. Chem. Chem. Phys. 2014, 16, 4679-4693.

15. Gadikota, G.; Swanson, E.J.; Zhao, H.; Park, A.-H.A. Experimental design and data analysis for accurate estimation of reaction kinetics and conversion for carbon mineralization. Ind. Eng. Chem. Res. 2014, 53, 6664-6676.

16. Julcour, C.; Bourgeois, F.; Bonfils, B.; Benhamed, I.; Guyot, F.; Bodénan, F.; Petiot, C.; Gaucher, É.C. Development of an attrition-leaching hybrid process for direct aqueous mineral carbonation. Chem. Eng. J. 2015, 262, 716-726.

17. Rigopoulos, I.; Petallidou, K.C.; Vasiliades, M.A.; Delimitis, A.; Ioannou, I.; Efstathiou, A.M.; Kyratsi, T. Carbon dioxide storage in olivine basalts: Effect of ball milling process. Powder Technol. 2015, 273, 220-229.

18. Oxtoby, D.W.; Freeman, W.A.; Block, T.F. Chemistry: Science of Change, 4th ed.; Brooks/Cole: Belmont, NY, USA, 2002.

19. Béarat, H.; McKelvy, M.J.; Chizmeshya, A.V.G.; Gormley, D.; Nunez, R.; Carpenter, R.W.; Squires, K.; Wolf, G.H. Carbon sequestration via aqueous olivine mineral carbonation: Role of passivating layer formation. Environ. Sci. Technol. 2006, 40, 4802-4808.

20. Chen, Z.-Y.; O'Connor, W.K.; Gerdemann, S.J. Chemistry of aqueous mineral carbonation for carbon sequestration and explanation of experimental results. Environ. Prog. 2006, 25, 161-166.

21. De Windt, L.; Devillers, P. Modeling the degradation of Portland cement pastes by biogenic organic acids. Cem. Concr. Res. 2010, 40, 1165-1174.

22. Chiang, Y.W.; Santos, R.M.; van Audenaerde, A.; Monballiu, A.; van Gerven, T.; Meesschaert, B. Chemoorganotrophic Bioleaching of Olivine for Nickel Recovery. Minerals 2014, 4, 553-564. 
23. O’Connor, W.K.; Dahlin, D.C.; Rush, G.E.; Gerdemann, S.J.; Penner, L.R.; Nilsen, D.N. Aqueous mineral carbonation-Mineral availability, pretreatment, reaction parametrics, and process studies. National Energy Technology Laboratory, US DOE. Available online: http://www. webcitation.org/query?url=https\%3A\%2F\%2Fwww.netl.doe.gov\%2FFile $\% 2520$ Library $\% 2$ FResearch\%2FCoal\%2FNETLAlbanyAqueousMineralCarbonation.pdf\&date=2015-07-26 (accessed on 26 July 2015).

24. Larachi, F.; Daldoul, I.; Beaudoin, G. Fixation of $\mathrm{CO}_{2}$ by chrysotile in low-pressure dry and moist carbonation: Ex-situ and in-situ characterizations. Geochim. Cosmochim. Acta 2010, 74, 3051-3075.

25. Qafoku, O.; Kovarik, L.; Kukkadapu, R.K.; Ilton, E.S.; Arey, B.W.; Tucek, J.; Felmy, A.R. Fayalite dissolution and siderite formation in water-saturated supercritical $\mathrm{CO}_{2}$. Chem. Geol. 2012, 332-333, 124-135.

26. Lieftink, D.J.; Geus, J.W. The preparation of silica from the olivine process and its possible use as a catalyst support. J. Geochem. Explor. 1998, 62, 1-3.

27. Lazaro, A.; Brouwers, H.J.H.; Quercia, G.; Geus, J.W. The properties of amorphous nano-silica synthesized by the dissolution of olivine. Chem. Eng. J. 2012, 211-212, 112-121.

28. Wiedenmann, D.; Zaitsev, A.N.; Britvin, S.N.; Krivovichev, S.V.; Keller, J. Alumoåkermanite, $(\mathrm{Ca}, \mathrm{Na})_{2}\left(\mathrm{Al}, \mathrm{Mg}, \mathrm{Fe}^{2+}\right)\left(\mathrm{Si}_{2} \mathrm{O}_{7}\right)$, a new mineral from the active carbonatite-nephelinite-phonolite volcano Oldoinyo Lengai, northern Tanzania. Miner. Mag. 2009, 73, 373-384.

29. Sanemasa, I.; Yoshida, M.; Ozawa, T. The dissolution of olivine in aqueous solution of inorganic acids. Bull. Chem. Soc. Jpn. 1972, 45, 1741-1746.

30. Terry, B. The acid decomposition of silicate minerals part I. Reactivities and modes of dissolution of silicates. Hydrometallurgy 1983, 10, 135-150.

31. Tzeferis, P.G.; Agatzini-Leonardou, S. Leaching of nickel and iron from Greek non-sulphide nickeliferous ores by organic acids. Hydrometallurgy 1994, 36, 345-360.

(C) 2015 by the authors; licensee MDPI, Basel, Switzerland. This article is an open access article distributed under the terms and conditions of the Creative Commons Attribution license (http://creativecommons.org/licenses/by/4.0/). 